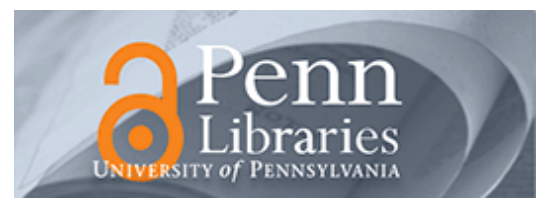

University of Pennsylvania

ScholarlyCommons

Operations, Information and Decisions Papers

Wharton Faculty Research

$10-2008$

\title{
Strategic Customer Behavior, Commitment, and Supply Chain Performance
}

Xuanming Su

University of Pennsylvania

Fuqiang Zhang

Follow this and additional works at: https://repository.upenn.edu/oid_papers

Part of the Operations and Supply Chain Management Commons, and the Other Social and Behavioral Sciences Commons

Recommended Citation

Su, X., \& Zhang, F. (2008). Strategic Customer Behavior, Commitment, and Supply Chain Performance. Management Science, 54 (10), 1759-1773. http://dx.doi.org/10.1287/mnsc.1080.0886

This paper is posted at ScholarlyCommons. https://repository.upenn.edu/oid_papers/157

For more information, please contact repository@pobox.upenn.edu. 


\title{
Strategic Customer Behavior, Commitment, and Supply Chain Performance
}

\begin{abstract}
This paper studies the impact of strategic customer behavior on supply chain performance. We start with a newsvendor seller facing forward-looking customers. The seller initially charges a regular price but may salvage the leftover inventory at a lower salvage price after random demand is realized. Customers anticipate future sales and choose purchase timing to maximize their expected surplus. We characterize the rational expectations equilibrium, where we find that the seller's stocking level is lower than that in the classic model without strategic customers. We show that the seller's profit can be improved by promising either that quantities available will be limited (quantity commitment) or that prices will be kept high (price commitment). In most cases, both forms of commitment are not credible in a centralized supply chain with a single seller. However, decentralized supply chains can use contractual arrangements as indirect commitment devices to attain the desired outcomes with commitment. Decentralization has generally been associated with coordination problems, but we present the contrasting view that disparate interests within a supply chain can actually improve overall supply chain performance. In particular, with strategic customer behavior, we find that (i) a decentralized supply chain with a wholesale price contract may perform strictly better than a centralized supply chain; (ii) contracts widely studied in the supply chain coordination literature (e.g., markdown money, sales rebates, and buyback contracts) can serve as a commitment device as well as an incentive-coordinating device; and (iii) some of the above contracts cannot allocate profits arbitrarily between supply chain members because of strategic customer behavior.
\end{abstract}

\section{Keywords}

strategic customer behavior, commitment, supply chains, newsvendor, rational expectations, decentralization

Disciplines

Operations and Supply Chain Management | Other Social and Behavioral Sciences 


\title{
Submitted to Management Science manuscript MS-0001-1922.65
}

\section{Strategic customer behavior, commitment, and supply chain performance}

\author{
Xuanming $\mathrm{Su}$ \\ Haas School of Business, University of California, Berkeley, CA 94720, xuanming@haas.berkeley.edu \\ Fuqiang Zhang \\ Paul Merage School of Business, University of California, Irvine, CA 92697, fzhang@uci.edu
}

\begin{abstract}
This paper studies the impact of strategic customer behavior on supply chain performance. We start with a newsvendor seller facing forward-looking customers. The seller initially charges a regular price but may salvage the leftover inventory at a lower salvage price after random demand is realized. Customers anticipate future sales and choose purchase timing to maximize their expected surplus. We characterize the rational expectations (RE) equilibrium, where we find that the seller's stocking level is lower than that in the classic model without strategic customers. We show that the seller's profit can be improved by promising that: either quantities available will be limited (quantity commitment) or prices will be kept high (price commitment). In most cases, both forms of commitment are not credible in a centralized supply chain with a single seller. However, decentralized supply chains can use contractual arrangements as indirect commitment devices to attain the desired outcomes with commitment. While decentralization has generally been associated with coordination problems, we present the contrasting view that disparate interests within a supply chain can actually improve overall supply chain performance. In particular, with strategic customer behavior, we find that: (i) a decentralized supply chain with a wholesale price contract may perform strictly better than a centralized supply chain; (ii) contracts widely studied in the supply chain coordination literature (e.g., markdown money, sales rebates, and buyback contracts) can serve as a commitment device as well as an incentive-coordinating device; and (iii) some of the above contracts cannot allocate profits arbitrarily between supply chain members due to strategic customer behavior.
\end{abstract}

\section{Introduction}

Consumers today have largely been trained to wait for sales. This is a general consensus, widely accepted by practitioners and academics alike. Year after year, market research organizations conduct surveys with holiday season shoppers and find that more than half of them plan to wait for the year-end sales. Together with competitive pressures, this has forced retailers to offer steeper 
discounts, earlier and earlier into the retail season (Byrnes and Zellner, 2004). The inevitable consequence is a vicious cycle: consumers expect increasingly generous discounts, and retailers fulfill these expectations by cutting deeper and deeper into their margins. Decreased profit margins challenge the ability of these businesses to provide an adequate level of retail service, and this leads to decreased customer satisfaction.

The retail industry has long recognized the critical impact of bargain-hunting behavior on the bottom-line, and the advent of markdown optimization offers an opportunity to tackle this issue directly (Sliwa, 2003). Markdown optimization balances supply and demand and increases the sellthrough rate by setting prices in response to available inventory. As a result, consumers may no longer benefit from blindly waiting for sales, because it is now more likely that their desired product will be sold out if they wait for too long. This approach has led to substantial profit increases at several major retailers such as Bloomingdale's and Gap (Kadet, 2004). These recent trends suggest that strategic consumer behavior is not only attracting attention in the retail industry, but active measures are also being adopted to lessen its negative impact.

Although the importance of strategic consumer behavior is widely acknowledged, there has been little research studying its implications on supply chain management. In view of this gap in the literature, this paper has three main objectives. First, we would like to develop a modeling framework to study strategic consumer behavior in supply chains. We begin with the classic newsvendor setting, which is a fundamental building block in the literature, and proceed to incorporate strategic demand into the model. Second, we would like to use this model to investigate the impact of strategic consumer behavior on supply chain performance. Although it is intuitively clear that the effect on firm profits is negative, the economic mechanisms underlying these effects need to be understood better. The third objective is prescriptive: when consumers are strategic, how can we better manage the supply chain? In a centralized setting, how should firms determine pricing and inventory decisions? In decentralized systems, how should the incentives of various parties (e.g., manufacturers, retailers, and consumers) be coordinated? 
Su and Zhang: Strategic customer behavior, commitment, and supply chain performance

Our model builds upon the classic newsvendor model. In the usual setup, the newsvendor faces a random aggregate demand $X$, chooses the stocking quantity $Q$, and the exogenous parameters are $p$ (regular price), $c$ (cost), and $s$ (salvage price). To incorporate strategic behavior among the consumers (in the demand pool $X$ ), we allow the consumers to either buy at the regular price $p$ or wait for the salvage price $s$. If there is inventory remaining at the salvage price, the consumers who wait may get a good deal; otherwise, they end up without the product. The newsvendor's decision variables are now $p$ (regular price) and $Q$ (quantity); these choices influence the consumers' to-buyor-to-wait decisions. This model captures the strategic interaction between the newsvendor and the consumers. With this model, we would like to characterize equilibrium outcomes (i.e., price, quantity, and consumers' purchase decisions).

The solution approach in this paper follows the rational expectations hypothesis, first proposed by Muth (1961). It states that economic outcomes do not differ systematically from what people expect them to be. Applying this concept to the present setting, we analyze the model above by looking for Rational Expectations (RE) equilibria, which satisfy: (i) given their expectations of future availability, consumers make their purchase (or waiting) decisions, (ii) given his expectations of consumers' willingness-to-pay, the newsvendor makes his pricing and stocking decisions, and (iii) everyone's expectations are consistent with actual outcomes. In this paper, we first derive the RE equilibrium for the newsvendor model, and then extend the concept to the case of decentralized supply chains. A decentralized supply chain consists of a single retailer and a single manufacturer. In this case, we assume that a contractual agreement between them is exogenously specified up front; this is consistent with the existing literature on supply chain contracting. Then the retailer and consumers play the RE equilibrium. In this way, equilibrium outcomes under decentralization can also be studied using our framework.

There are three main results in this paper. First, we show that when consumers are strategic, a centralized supply chain may perform strictly worse than a decentralized supply chain. This is because contrary to popular belief, double marginalization may benefit decentralized systems: a reduced stocking quantity intensifies the threat of stock-outs and thus also increases consumers' 
willingness-to-pay. Centralized systems, however, are unable to impose similar threats, which are not credible as they will not be fulfilled in RE equilibrium. This challenges the conventional wisdom that centralized systems provide a gold standard for supply chains to strive for, because when consumers are strategic, it is possible to surpass this benchmark.

Next, we propose two alternative benchmarks that serve as performance targets. We have already seen that profits can be enhanced when firms use the threat of stock-outs to increase consumers' willingness-to-pay; alternatively, another means to achieve the same end is to guarantee that future prices will remain high. These two strategies (quantity-commitment and price-commitment, respectively) induce consumers to purchase early at a higher price, by maintaining the exclusivity of the product. In our analysis, we solve for the RE equilibrium between the consumers and the newsvendor under price and quantity-commitment. We confirm that commitment power increases profits, and that each form of commitment is preferred under different situations. These two commitment benchmarks offer a fresh perspective on the design of decentralized supply chains: with strategic customer behavior, instead of striving for centralized outcomes, we should work towards the commitment outcomes.

Finally, we show that these performance targets can indeed be attained. By structuring appropriate contractual agreements between supply chain parties, decentralized systems can achieve the price-commitment and quantity-commitment outcomes. In other words, supply contracts function indirectly as commitment devices. We emphasize "indirectly" because firms do not (and often can not) make any explicit promises to consumers (e.g., the promise by a firm not to mark down price may not be credible because after the regular season, the firm has incentives to salvage the leftover products at a lower price). Instead, they use contractual arrangements to "change the rules of the game" so as to attain the desired equilibrium outcomes. From a mechanism design standpoint, it is not surprising to find that as long as the class of admissible contractual mechanisms is large enough, significantly better outcomes can be implemented. However, in our case, it turns out that the following types of contracts are sufficient to implement the commitment outcomes: wholesale 
price contracts, buy-backs, markdown money, and sales rebates. In addition, we identify several features of these contracts that are novel in the current setting with strategic consumers. For instance, buy-backs serve to implement price-commitment whereas markdown money empowers the retailer with quantity-commitment. Also, strategic consumer behavior sometimes imposes constraints on how profits must be allocated between the supply chain parties.

The remainder of this paper is structured as follows. Section 2 provides a literature review. Section 3 introduces our newsvendor model with strategic consumers and analyzes the value of commitment. Sections 4 and 5 demonstrate how to attain our two profit benchmarks (under quantity-commitment and price-commitment, respectively) using appropriate contractual mechanisms. Section 6 considers several extensions, and Section 7 concludes.

\section{Literature Review}

When making a purchase decision, consumers choose from various alternatives, including the option of delaying the purchase. For example, whether or not a consumer makes a purchase depends on her expectations of what future prices will be. The forward-looking behavior of consumers has been widely documented in the consumer behavior literature, for example, Jacobson and Obermiller (1990), Krishna, Currim, and Shoemaker (1991), Krishna (1994), and Ho, Tang, and Bell (1998), among others. This stream of research focuses on consumers' impressions of retailers' pricing patterns and its impact on consumers' purchasing decisions.

Given its prevalence and importance, strategic consumer behavior has been studied extensively across various disciplines. There is a stream of research in economics and marketing that examines durable goods markets with strategic consumers. This has been inspired by Coase (1972), who showed that durable goods monopolists will end up earning zero profits because as long as prices are above marginal cost, strategic consumers will anticipate and wait for price reductions. Bulow (1982) contributes the important insight that a durable good monopolist prefers to rent his product rather than to sell it, because this avoids the competition from second-hand markets operated primarily by strategic consumers. Two recent studies that are most relevant to this paper are Desai, Koenigsberg, 
and Purohit (2004), and Arya and Mittendorf (2005), both of which compare centralized and decentralized distribution channels for durable goods under strategic consumer behavior. Desai, Koenigsberg, and Purohit show that under certain conditions, strategic decentralization through the addition of a retailer in the distribution channel can increase a manufacturer's profits, if the manufacturer can commit to future wholesale prices with the retailer. Arya and Mittendorf show that the benefits of decentralization are robust against changes in the manufacturer's ability to commit. Our paper is similar in spirit because we also find that a decentralized supply chain may outperform a centralized one as a result of strategic consumer behavior, but we demonstrate this finding in a different setting with seasonal products and stochastic demand (rather than durable goods with deterministic demand).

Strategic consumer behavior has recently been studied by operations management researchers. In particular, the literature on dynamic pricing of finite inventories is related to our paper. Aviv and Pazgal (2005) study optimal pricing of a seasonal product with the presence of forward-looking consumers. There is a single price reduction and the authors examine the optimal timing and extent of discounts. Elmaghraby, Gulcu, and Keskinocak (2004) investigate optimal markdown mechanisms in the presence of rational customers with multi-unit demands. Zhou, Fan, and Cho (2005) analyze optimal customer responses when facing an exogenously specified dynamic pricing policy. Gallien (2005) shows that the optimal prices should increase over time when selling a finite inventory to customers arriving over an infinite horizon. Su (2005) considers a heterogenous population of strategic as well as myopic customers, and shows that depending on the customer composition, optimal price paths could involve either markups or markdowns. Yu, Kapuscinski, and Ahn (2006) study advance selling with limited capacity under various demand scenarios. These papers assume that the initial capacity is exogenously given, which differs from our model. van Ryzin and Liu (2005) study quantity decisions instead of price decisions in a capacity rationing model with strategic customers. Yin and Tang (2006) analyze a fashion retailer's ordering decision in a model where strategic customers arrive to the store according to a Poisson process and the prices are announced before the selling season starts. They focus on the impact of two different 
Su and Zhang: Strategic customer behavior, commitment, and supply chain performance

display formats (display all vs. display one) on the seller's expected profits. There are also papers that consider strategic consumers in dynamic auction settings (see, e.g., Caldentey and Vulcano, 2004, and Gallien and Gupta, 2005). All the above papers only study the interaction between strategic consumers and a single seller, while our paper also considers the vertical relationship between manufacturers and retailers.

Our paper builds on the well-known newsvendor problem: find the optimal order quantity that maximizes the seller's expected profit under probabilistic demand. There have been several recent developments of newsvendor model that are most relevant. Petruzzi and Dada (1999) summarize and extend the newsvendor model literature with pricing decisions. In their model, the aggregate demand is characterized as a function of the retail price together with a random shock. We also consider pricing decisions for the retailer, but in our model individual consumers may react rationally to the retailers' ordering quantity as well as prices. Dana and Petruzzi (2001) study a newsvendor problem in which customer demand is dependent on both price and inventory level. In their model, customers who visit the newsvendor forego an exogenous outside option (or equivalently, they face a traveling cost). A higher likelihood of availability induces more customer visits and stimulates demand. This yields a higher optimal stocking level for the newsvendor. In contrast, in our model, strategic customer behavior leads to a lower optimal stocking level. This is because strategic waiting by customers compromise the retailer's ability to charge a high price in the regular selling season and a remedy for the retailer is to limit the ordering quantity so that customers are discouraged from waiting for the sale. Cachon and Kok (2004) re-interpret the salvage price as a market-clearing price. They endogenize the clearance pricing decision and focus on how to estimate the salvage value from historical data. A literature review on newsvendor model and its extensions can be found in Silver, Pyke, and Peterson (1998) \& Khouja (1999).

There exists an enormous literature on supply chain contracting with a newsvendor retailer. The focus is on how to design a contractual relationship between the retailer and supplier to maximize supply chain efficiency. It has been shown that a variety of contracts can eliminate double marginalization by aligning firms' incentives. Some of the contracts can also split the supply chain 
profit arbitrarily between firms. For a detailed survey of the literature on supply chain contracting, the readers are referred to Cachon (2003). It is worth pointing out that so far the customary practice has been to use the centralized optimal solution as the benchmark to evaluate various contracts. However, with the presence of strategic consumers, commitment becomes a critical issue in addition to centralization and the centralized optimal solution benchmark may not be appropriate any more.

\section{Newsvendor Model with Strategic Customers 3.1. Basic setup}

This paper builds upon the newsvendor inventory model. There is a single seller who must determine how many units of a product to stock. The seller faces a random demand $X \geq 0$, which has distribution $F$ and density $f$. We assume that the demand distribution has an increasing failure rate, that is, $f(x) /(1-F(x))$ is increasing in $x$; this assumption is satisfied by many commonly observed distributions. For technical reasons, we also assume that $f$ is continuous, has a connected support, and $f(0)>0$. Each unit of the product costs $c$ but is valued by customers at $v$. That is, $v$ is customers' utility from consuming the product. Leftover units can be sold in an exogenous salvage market at $s$ per unit. We assume that $s<c<v$.

Our model departs from the classic setup by introducing strategic customers. Specifically, customers recognize that the product may become available on the salvage market at price $s$. In order to maximize individual expected surplus, customers choose between buying immediately (at full price) or waiting for the sale (at salvage price). If the regular selling price is too high, customers may find it worthwhile to wait for the sale, even if the product may be sold out by then. Let $r$ denote customers' reservation price or their willingness to pay in the regular selling season. Clearly, there is $r<v$ if there is a positive probability that customers can get the product at the lower salvage price $s$. This setup can directly be compared against the standard newsvendor model, in which the selling price is $v$ and all customers buy at this price upon the realization of demand $X$.

We shall adopt the following sequence of events. First, the seller privately forms his beliefs over customers' reservation prices, and then optimally chooses the price and quantity given these beliefs. We assume that customers may observe the selling price but not the stocking quantity. 
Su and Zhang: Strategic customer behavior, commitment, and supply chain performance

Then, customers privately form beliefs over their chances of obtaining the product on the salvage market, and then form their reservation prices based on these beliefs. Next, the random demand $X$ is realized. Then, sales occur at the full price $p$ (provided that the selling price $p$ does not exceed consumers' reservation price $r$ ). Finally, all remaining units are sold at the salvage price $s$.

Based on this chronology, we first describe the consumer's decision problem. Consider a particular consumer who forms the belief that he will obtain the product with probability $\xi_{\text {prob }}$ if he waits for the sale. (Note that here a point estimate of the availability probability is sufficient since the distribution of the possibles outcomes is binary: the product is either available or not). Based on these expectations, the consumer's expected surplus if he faces an actual regular price $p$ is $\max \left\{v-p,(v-s) \xi_{\text {prob }}\right\}$. The first term is his surplus from buying at the regular price $p$, and the second term is his expected surplus if he waits for the sale, where there is probability $\xi_{\text {prob }}$ that he earns surplus $v-s$ and probability $1-\xi_{\text {prob }}$ that he earns zero surplus (if the product is out of stock). Since the consumer chooses the more attractive option between buying and waiting, he will buy at price $p$ if and only if $v-p \geq(v-s) \xi_{\text {prob }}$. In other words, given his expectations $\xi_{\text {prob }}$, the consumer's reservation price for the product is $r\left(\xi_{\text {prob }}\right)=v-(v-s) \xi_{\text {prob }}$. For tractability, we make the following two assumptions. First, we consider homogeneous customers who share the same beliefs $\xi_{\text {prob }}$ and the same reservation price $r$. Second, we assume that consumers are risk neutral and they do not discount future payoffs. In Section 6 we relax these assumptions and consider more elaborate models of consumer behavior to demonstrate the robustness of our results.

Next, we consider the seller's decision problem. The two decisions are stocking quantity $Q$ and regular selling price $p$. Suppose that the seller expects that all customers have a reservation price $\xi_{r}$. Given these beliefs, it is clear that he will choose price $p=\xi_{r}$ and quantity $Q(p)=\arg \max _{Q} \Pi(Q, p)$, where $\Pi(Q, p)=(p-s) E(X \wedge Q)-(c-s) Q$ is the newsvendor profit function, which has an unique maximizer. We use " $\wedge$ " throughout the paper for the minimum operator. Notice that given beliefs $\xi_{r}$, the seller is essentially considering facing a standard newsvendor problem with a fixed price. 


\subsection{Rational expectations equilibrium}

Definition 1. A rational-expectations equilibrium $\left(p, Q, r, \xi_{\text {prob }}, \xi_{r}\right)$ satisfies the following:

(i) $r=v-(v-s) \xi_{\text {prob }}$, (ii) $p=\xi_{r}$, (iii) $Q=\arg \max _{Q} \Pi(Q, p)$, (iv) $\xi_{\text {prob }}=F(Q)$, (v) $\xi_{r}=r$.

Conditions (i), (ii), and (iii) assert that under expectations $\xi_{\text {prob }}$ and $\xi_{r}$, the seller and all consumers will rationally choose the appropriate utility-maximizing actions, as discussed above. The final two conditions require that expectations must be consistent with outcomes. In (iv), the expectations $\xi_{\text {prob }}$ must concur with the actual probability of obtaining the product if an individual consumer waits for the sale. This actual probability can be calculated as follows. In equilibrium, the seller prices the product at consumers' reservation price, so all consumers will buy the product. Therefore, if an individual consumer waits instead, this consumer will obtain the product if and only if $X \leq Q$, which occurs with probability $F(Q)$, as shown in (iv). Here, we have implicitly assumed efficient rationing: customers who wait for the sale have the highest priority to receive the product in the salvage market. This is reasonable because customers who are interested in a particular product and eagerly waiting for a sale are also the ones who are more likely to get the product when the sale actually takes place. Finally, in (v), the seller must correctly anticipate consumers' reservation price.

Notice that the conditions for a rational expectations (RE) equilibrium in Definition 1 can be reduced to a pair of equations in $p$ and $Q$ only: $p=v-(v-s) F(Q)$, and $Q=\arg \max _{Q} \Pi(Q, p)$. These two conditions will be used to explicitly characterize the RE equilibrium below.

Proposition 1. In the RE equilibrium, all consumers buy immediately, and the seller's price and quantity are characterized by $p_{c}=s+\sqrt{(v-s)(c-s)}, \bar{F}\left(Q_{c}\right)=\sqrt{\frac{c-s}{v-s}}$.

All proofs are given in an online appendix. Here, we have used $\bar{F}$ to denote $1-F$, and the subscript $c$ in $p_{c}$ and $Q_{c}$ stands for "centralized" (since we are considering a centralized system with a single seller). We will also use $\Pi_{c}$ to denote the seller's profit under the RE equilibrium.

It is instructive to compare the equilibrium price and quantity in our model with that in the classical newsvendor model, where customers are not strategic and are willing to pay their valuation $v$ for the product (so the seller also charges $v$ ). In terms of price, the equilibrium price 
$p_{c}$ must lie between $c$ and $v$, since $p_{c}-s$ is the geometric mean of $v-s$ and $c-s$. Unsurprisingly, strategic consumer behavior forces the seller to price below $v$. Next, in terms of quantity, the equilibrium stocking quantity $Q_{c}$ is also lower than the optimal stocking quantity $Q_{0}$ in the standard newsvendor model. Observe that $Q_{0}>Q_{c}$ because $\bar{F}\left(Q_{0}\right)=\frac{c-s}{v-s}<\sqrt{\frac{c-s}{v-s}}=\bar{F}\left(Q_{c}\right)$. When confronted with strategic customers, the seller lowers his stocking quantity. This is because the seller hopes to increase customers' willingness-to-pay by restricting the availability of the product and maintaining an image of exclusivity. Generating scarcity and competition among buyers is quite a natural strategy to adopt. It also arises in other contexts: for example, in auctions, an increased number of bidders often induces more aggressive bidding behavior; see, e.g., Bulow and Klemperer (1996) and Vulcano, van Ryzin, and Maglaras (2002).

\subsection{Value of commitment}

Can the seller do better than the RE equilibrium outcome described above? Yes, provided that he is able to make binding commitments on his own actions. In this section, we consider two distinct types of commitment power: quantity-commitment (keeping quantities low) and price-commitment (keeping prices high). Practical examples of quantity-commitment include limited editions of cars, furniture, and collectors' items, while price-commitment may arise in the form of "one-price" or "no-haggle" policies. Both strategies may increase the seller's profits by guaranteeing to customers that his product is sufficiently exclusive: it is not available in large quantities and it cannot be purchased at low prices. The seller's optimal profit levels under quantity-commitment and pricecommitment will be used as profit benchmarks for the remainder of our analysis.

We begin by discussing quantity-commitment. Suppose the seller has at his disposal some commitment device, which convinces customers that exactly $Q$ units of his product will be available for the entire time horizon of relevance. This commitment device could take the form of advertising campaigns, long-term reputation concerns, or supply-side constraints, but we do not model it explicitly. Given that $Q$ units are available, customers no longer need to form rational expectations $\xi_{\text {prob }}$ because they know for sure that if they wait for the sale (while all other customers buy), 
their chances of getting the product on the salvage market is $F(Q)$. In other words, when the seller commits to sell $Q$ units, customers are willing to pay (and the seller also charges) price $p(Q)=$ $v-(v-s) F(Q)$. Given this selling price, the seller's profits, as a function of the quantity $Q$ that he commits to, is $\Pi_{q}(Q)=(p(Q)-s) E(X \wedge Q)-(c-s) Q=(v-s) \bar{F}(Q) E(X \wedge Q)-(c-s) Q$. The seller will thus stock the optimal quantity $Q_{q}^{*}=\arg \max _{Q} \Pi_{q}(Q)$ and charge price $p_{q}^{*}=v-(v-s) F\left(Q_{q}^{*}\right)$, and the corresponding optimal profit level under quantity-commitment is denoted $\Pi_{q}^{*}$; the subscript $q$ stands for "quantity-commitment." Here, quantity-commitment allows the seller to actively manipulate the selling price $p(Q)$ as a function of the chosen quantity $Q$; on the other hand, in the absence of quantity-commitment, the price $p$ is determined by equilibrium rational expectations.

Lemma $1 . \Pi_{q}(Q)$ has a unique maximizer $Q_{q}^{*}$.

We next compare the quantity-commitment optimal outcome with the RE equilibrium outcome.

Proposition 2. (i) $Q_{q}^{*} \leq Q_{c}$ and $\Pi_{q}^{*} \geq \Pi_{c}$.

(ii) For fixed $s$ and $v$, there exist thresholds $c_{l}$ and $c_{h}\left(c_{l} \leq c_{h}\right)$ such that $\Pi_{q}^{*}-\Pi_{c}$ is decreasing in $c$ for $c \leq c_{l}$ and $c \geq c_{h}$.

(iii) For fixed $c$ and $s$, there exist thresholds $v_{l}$ and $v_{h}\left(v_{l} \leq v_{h}\right)$ such that $\Pi_{q}^{*}-\Pi_{c}$ is increasing in $v$ for $v \leq v_{l}$ and $v \geq v_{h}$.

Result (i) in Proposition 2 confirms our earlier statement that quantity-commitment enhances seller's profits. This is done by committing to a stocking quantity $Q_{q}^{*}$ that is lower than the RE equilibrium $Q_{c}$. Recall that in the RE equilibrium, the seller has already restricted availability by stocking at a level $Q_{c}$ that is lower than the corresponding quantity $Q_{0}$ in the absence of strategic customers. Our current result tells us that the seller can do better by limiting his available quantities even further. Indeed, creating artificial shortages is not an uncommon practice. For instance, Zara, one of the largest Spanish fashion retailers, is well-known for limiting production quantities to induce customers to pay the regular selling prices (Ferdows, Lewis, and Machuca, 2005). Furthermore, popular toys and electronic gadgets routinely go out of stock every holiday season (see Wingfield and Guth, 2005). In these cases, scarcity also serves as a marketing tool in 
Su and Zhang: Strategic customer behavior, commitment, and supply chain performance

generating hype and allure, which further increases the desirability of the product. Results (ii) and (iii) characterize the impact of model parameters on the value of commitment. They suggest that quantity commitment tends to be more valuable as the product becomes more profitable (either $v$ increases or $c$ decreases).

We stress that an external commitment device is critical in realizing the optimal quantity $Q_{q}^{*}$. The seller's promises, by themselves, are not credible, because when the seller lacks a commitment device, the quantity $Q_{q}^{*}$ cannot be sustained in a RE equilibrium. To see this, note from Definition 1 that in order to sustain $Q_{q}^{*}$ in equilibrium, the required expectations are $\xi_{\text {prob }}=F\left(Q_{q}^{*}\right)$ and $\xi_{r}=r$, and the required selling and reservation prices are $p=r=v-(v-s) F\left(Q_{q}^{*}\right)$. This set of values is the only candidate that satisfy conditions (i), (ii), (iv), and (v) in Definition 1, but with these values, the remaining condition (iii) contradicts the definition of $Q_{q}^{*}$. Intuitively, this means that the seller has an incentive to deviate from stocking the quantity $Q_{q}^{*}$ once the market believes in it, so these expectations will not be formed in the first place. Specifically, under the expectations that only $Q_{q}^{*}$ is available, customers would be willing to pay $p\left(Q_{q}^{*}\right)$, but once customers are willing to pay this much, it is in the seller's interests to raise the stocking level above $Q_{q}^{*}$, so the initial expectations of $Q_{q}^{*}$ would have been inconsistent and cannot be part of a RE equilibrium. However, this problem vanishes if the seller possesses some external commitment device.

Next, we turn to price-commitment. Suppose that the seller can credibly commit to future prices after demand has been realized. It is sufficient to consider the case in which the seller commits to maintain ex-post prices at exactly $v$. (If guaranteed ex-post prices are strictly between $v$ and $s$, the seller can do better by instead promising $v$ because this decreases customers' option value of waiting and increases their willingness-to-pay; if the guaranteed ex-post price is $s$, it is as good as none since we are back to the RE equilibrium.) Now, committing to maintain prices at $v$ is equivalent to eliminating the markdown opportunity provided by the salvage market. If these promises were credible, customers will be willing to pay $v$ at the start. Therefore, under pricecommitment, our model reduces to the standard newsvendor model (with zero salvage value). The seller charges $p_{p}^{*}=v$ and his profit function is $\Pi_{p}(Q)=v E(X \wedge Q)-c Q$. The optimal selling 
quantity is $Q_{p}^{*}=\arg \max _{Q} \Pi_{p}(Q)$ and the optimal profit level is $\Pi_{p}^{*}$. Here, the subscript $p$ stands for "price-commitment." The following proposition compares the performance of price commitment to the RE equilibrium outcome.

Proposition 3. (i) For fixed $s$ and $v$, there is a threshold $c_{l}$ such that $\Pi_{p}^{*} \geq \Pi_{c}$ for $c \leq c_{l}$ and there is a threshold $c_{h}$ such that $\Pi_{p}^{*} \leq \Pi_{c}$ for $c \geq c_{h}$. In addition, there exist thresholds $\hat{c}$ such that $\Pi_{p}^{*}-\Pi_{c}$ is decreasing in $c$ for $c \leq \hat{c}$.

(ii) For fixed $c$ and $s$, there exists a threshold $v_{l}$ such that $\Pi_{p}^{*} \leq \Pi_{c}$ for $v \leq v_{l}$ and there is a threshold value $v_{h}$ such that $\Pi_{p}^{*} \geq \Pi_{c}$ for $v \geq v_{h}$. In addition, there exist thresholds $\hat{v}$ such that $\Pi_{p}^{*}-\Pi_{c}$ is increasing in $v$ for $v \geq \hat{v}$.

Proposition 3 shows that price-commitment may increase the seller's profits above the RE equilibrium level. Specifically, the inequality $\Pi_{p}^{*} \geq \Pi_{c}$ holds when the production cost $c$ is relatively low and when the valuation $v$ is relatively high. However, there also exist situations where $\Pi_{p}^{*}<$ $\Pi_{c}$. Therefore, unlike quantity-commitment, price-commitment is not unambiguously beneficial. Proposition 3 also sheds light on when price commitment is valuable: under certain conditions, price commitment tends to be more valuable when the product becomes more profitable (either $v$ increases or $c$ decreases).

For the remainder of this section, we compare quantity-commitment and price-commitment.

\section{Proposition 4.}

(i) For fixed $c$ and $v$, there is a threshold $\hat{s} \geq 0$ such that $\Pi_{q}^{*} \geq \Pi_{p}^{*}$ if and only if $s \geq \hat{s}$.

(ii) For fixed $c$ and $s$, there is a threshold $v_{l}$ such that $\Pi_{q}^{*} \geq \Pi_{p}^{*}$ for $v \leq v_{l}$ and there is a threshold value $v_{h}$ such that $\Pi_{p}^{*} \geq \Pi_{q}^{*}$ for $v \geq v_{h}$.

This result states that quantity-commitment is preferred over price-commitment when customer valuation $v$ is low and the salvage value $s$ is high (i.e., both are close to production cost $c$ ). One interpretation, as follows, draws upon the comparison between mass and niche markets. Quantitycommitment is preferred in mass markets: in these environments, the product is tailored to the average consumer and there is ample salvage opportunities (so $v$ and $s$ are close together). On the 
other hand, there are also niche markets, which target specific high-end customer segments, but the resulting degree of customization may constrain the transfer of the product to alternative sources of demand (so $v$ and $s$ are far apart); under these conditions, price-commitment is preferred.

Quantity-commitment and price-commitment are both desirable strategies that sometimes arise in practice. However, in most situations, these strategies may not be feasible because the seller lacks an appropriate commitment device. In this case, what can the seller do? Our analysis thus far suggests that the seller would have to contend with the RE equilibrium outcome. This may be true in a centralized system (single seller), but not for decentralized systems. In the next sections, we show that contractual arrangements between supply chain parties can serve as a surrogate commitment device, so as to attain the optimal profit benchmarks $\Pi_{q}^{*}$ and $\Pi_{p}^{*}$ with commitment. As a result, a decentralized supply chain may yield higher profits than a centralized supply chain.

\section{Achieving Quantity Commitment in Decentralized Supply Chains}

In the previous section, customers purchase the product from a single seller. This section extends the newsvendor model to a supply chain setting. That is, we consider a manufacturer distributing a product through a retailer. In this context, we interpret $c$ as the manufacturer's production cost, $s$ as the retailer's salvage value, and $v$ and $X$ characterize market demand in the same way as before. The sequence of events is as follows: first, the contractual agreements between the manufacturer and the retailer are exogenously established; then, the retailer and customers make their pricing, stocking, and purchase decisions according to a RE equilibrium; finally, demand is realized during the selling season and unsold products are salvaged. In this decentralized setting, we assume that the manufacturer and the retailer are independent firms acting according to their own interests. Our goal is to design supply contracts so as to attain the profit benchmarks of a centralized system with quantity-commitment, $\Pi_{q}^{*}$.

We begin by analyzing the simplest contract: a pure wholesale price contract. Then, we will also analyze markdown allowances, buybacks, and linear sales rebates. These contracts are widely used and relatively simple to analyze (since payments depend linearly on quantities). We demonstrate that under appropriate contractual parameters, the decentralized supply chain can attain 
the quantity-commitment benchmark $\Pi_{q}^{*}$.

\subsection{Wholesale price contracts}

A wholesale price contract specifies the unit price $w(w \geq c)$ the manufacturer charges the retailer.

We assume that the wholesale price $w$ is determined through some negotiation process between the manufacturer and the retailer, which is beyond the scope of this paper. However, we may consider $w$ a proxy of firms' relative bargaining power: a higher $w$ reflects a more favorable position for the manufacturer. See Cachon (2003) for more discussion about wholesale price contracts.

Under a wholesale price contract, the retailer's profit function is $\Pi_{w}^{r}(Q, p)=(p-s) E(X \wedge Q)-$ $(w-s) Q$. Here, the subscript $w$ stands for "wholesale price" and the superscript $r$ stands for "retailer." (Later, we will use the superscript $m$ to refer to the manufacturer's profit function.) The RE equilibrium between the retailer and the consumers is derived similarly as before. Therefore, following the argument of Proposition 1, the retailer's order quantity $Q_{w}$ and retail price $p_{w}$ in $\mathrm{RE}$ equilibrium is given by $\bar{F}\left(Q_{w}\right)=\frac{w-s}{p_{w}-s}=\sqrt{\frac{w-s}{v-s}}$, and $p_{w}=s+(v-s) \bar{F}\left(Q_{w}\right)=s+\sqrt{(v-s)(w-s)}$. In this $\mathrm{RE}$ equilibrium, the profits to the retailer and the manufacturer are given respectively by $\Pi_{w}^{r}=\left(p_{w}-s\right) E\left(X \wedge Q_{w}\right)-(w-s) Q_{w}=(v-s) \bar{F}\left(Q_{w}\right) E\left(X \wedge Q_{w}\right)-(v-s) \bar{F}^{2}\left(Q_{w}\right) Q_{w}$ and $\Pi_{w}^{m}=Q_{w}(w-c)=Q_{w}\left[(v-s) \bar{F}^{2}\left(Q_{w}\right)-(c-s)\right]$, and total supply chain profits are $\Pi_{w} \equiv \Pi_{w}^{r}+\Pi_{w}^{m}=$ $(v-s) \bar{F}\left(Q_{w}\right) E\left(X \wedge Q_{w}\right)-(c-s) Q_{w}$.

Observe that the wholesale price $w$ can be used as a control lever for the supply chain to induce a particular equilibrium stocking quantity. The reasoning is as follows. Since the equilibrium quantity $Q_{w}$ is decreasing in $w$, there is a one-to-one relationship between $Q_{w} \in\left[0, Q_{c}\right]$ and $w \in[c, v]$. (Recall that $Q_{c}$ is the RE equilibrium quantity in the centralized system.) Therefore, by varying $w$ between $c$ and $v$, the system can realize any equilibrium quantity within the corresponding range. Although this particular quantity has to conform to the requirements of an RE equilibrium, it is as if the supply chain could specify it at the outset. In this sense, a simple wholesale price contract provides the supply chain with some degree of quantity-commitment power.

To emphasize the dependence of these equilibrium quantities on the wholesale price $w$, we sometimes write $Q_{w}(w), p_{w}(w), \Pi_{w}^{r}(w), \Pi_{w}^{m}(w), \Pi_{w}(w)$. It turns out that quantity-commitment power 
Su and Zhang: Strategic customer behavior, commitment, and supply chain performance

can significantly enhance supply chain profits. This is made precise in the next proposition, which follows from Lemma 1 and Proposition 2.

Proposition 5. There exists some $w^{*} \in(c, v)$ such that:

(i) For every $w \in\left(c, w^{*}\right]$, equilibrium total profits in the decentralized system under the wholesale price contract $w$ exceed equilibrium profits in the centralized system, that is, $\Pi_{w}(w) \geq \Pi_{c}$.

(ii) The wholesale price contract $w=w^{*}$ enables the decentralized system to achieve the optimal profit under quantity commitment $\Pi_{q}^{*}$.

This is a surprising result: Proposition 5(i) states that the profit of a centralized supply chain is dominated by the profits of a decentralized supply chain, under an array of wholesale price contracts. In this paper, by "centralized" we mean the supply chain is controlled by a central planner who wishes to maximize the entire supply chain's profit. It has been a customary practice to use centralized management as a benchmark to study channel efficiency in the operations and marketing literature. Proposition 5(i) delivers a message that the centralized optimal profit may not always be the highest possible profit that a supply chain can achieve. In particular, there have been numerous studies addressing the inefficiency caused by double marginalization: i.e., when $w>c$, the retailer orders less than the optimal quantity for the entire supply chain. In contrast, we present a model in which increasing the wholesale price beyond $c$ actually improves the supply chain's profit. The reason is that a higher wholesale price will enable the retailer to charge a higher retail price to forward-looking consumers in equilibrium, and varying the wholesale price only alters the transfer payment between the supply chain members.

Proposition 5(ii) goes one step further. It states that a decentralized supply chain can achieve $\Pi_{q}^{*}$, the optimal profit under the quantity commitment, by using a wholesale price contract $w=w^{*}$. This wholesale price induces the optimal quantity $Q_{q}^{*}$ in equilibrium. A similar situation where a wholesale price contract can coordinate a supply chain is when horizontal competition is present. For example, Netessine and Zhang (2005) demonstrate that in a distribution channel with a manufacturer and multiple retailers, the substitution effect among the retailers can offset the double 
marginalization effect and thus retain the supply chain optimal outcome. The driving forces underlying our model are different: we have strategic consumers on top of double marginalization, and a wholesale price contract can serve as a coordination device to balance these two opposite forces.

Although the wholesale price contract $w^{*}$ allows the supply chain to attain the profit benchmark $\Pi_{q}^{*}$, it enforces a particular division of profits between the retailer and the manufacturer (their shares are $\Pi_{w}^{r}\left(w^{*}\right)$ and $\Pi_{w}^{m}\left(w^{*}\right)$ respectively). Yet, each individual party may prefer some wholesale price other than $w^{*}$ and may negotiate for their preferences. Since it may not be possible for both parties to agree upon the wholesale price $w^{*}$, it now becomes important to understand each party's preferences over alternative wholesale prices.

We proceed by asking the following two questions. First, if given the choice, what wholesale price would the retailer and the manufacturer select? In other words, how are the quantities $w^{r} \in$ $\arg \max _{w} \Pi_{w}^{r}(w)$ and $w^{m} \in \arg \max _{w} \Pi_{w}^{m}(w)$ characterized, and are they unique? Second, how do these unilaterally-preferred wholesale prices $w^{r}$ and $w^{m}$ compare with the system-optimal wholesale price $w^{*}$ ? The following lemma deals with these questions.

Lemma 2. (i) The maximizers $w^{r}$ and $w^{m}$ are unique. (ii) $w^{r}<w^{*}<w^{m}$.

Consistent with this result, Figure 1 shows a numerical example with the retailer, manufacturer, and supply chain profit functions (against wholesale price $w$ ) and their maximizers.

We are interested in characterizing the set of Pareto optimal wholesale price contracts. A contract is Pareto optimal if there exists no alternative such that some firm is strictly better off and no firm is worse off. We have the next proposition, which follows from Lemmas 1 and 2.

Proposition 6. The set of Pareto optimal wholesale price contracts is $w \in\left[w^{r}, w^{m}\right]$. In particular, if $w^{r}>c$, then the wholesale price $w=c$ is Pareto dominated by any $w \in\left[c, w^{r}\right]$.

The proposition sheds some light on how the allocation of bargaining power affects supply chain efficiency: since $w^{r}<w^{*}<w^{m}$, the supply chain optimum is achieved somewhere in the middle, and any extreme allocation of bargaining power is not good for the supply chain. This in contrast with some of the existing results in the literature. With wholesale price contracts, Lariviere and 


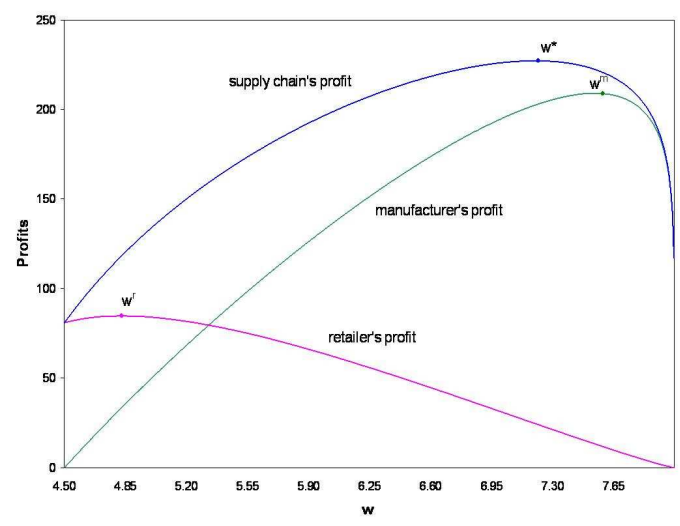

Figure 1 Comparison of the profit functions (demand follows a normal distribution $N(100,400)$ and parameter values are $c=4.5, s=4$, and $v=8$ ).

Porteus (2001) acknowledge that an increase in retail power can improve supply chain performance. When studying the pull contracts (i.e., the retailer chooses the wholesale price and orders only as needed during the selling season), Cachon (2004) finds that the opposite is true: increasing the supplier's bargaining power (in the form of a higher minimum profit requirement) would increase supply chain efficiency. Our model provides a more balanced view by noting that a well-balanced bargaining power may achieve the most efficient outcome for a supply chain. Now, consider the following question: if the retailer has absolute bargaining power, will it offer a wholesale price $w=c$ and squeeze the manufacturer's profit to zero? Not necessarily. Note that the problem faced by the retailer with varying wholesale price $w$ is equivalent to the problem faced by the single seller with varying production cost $c$. If we view the seller's profit $\Pi_{c}$ as a function of $c$, then $w^{r}$ is essentially the production cost that maximizes the seller's profit. Therefore, if $w^{r}>c$ (i.e., the profit-maximizing production cost is greater than the actual cost), then the contract with $w=c$ is Pareto dominated by any $w \in\left[c, w^{r}\right]$ (such as in Figure 1). That is, under certain conditions, both the retailer and the manufacturer may prefer a higher wholesale price. The fact that the retailer may voluntarily invite a higher wholesale price is quite interesting.

\subsection{Markdown money contracts}

We now study markdown money contracts. Apart from realizing the profit benchmark $\Pi_{q}^{*}$ in decentralized systems, they also offer additional flexibility in that they permit arbitrary profit allocations. 
With a markdown money contract the manufacturer charges the retailer a unit price $w_{m}$, but pays the retailer $m$ per unit salvaged at the end of the season. We require $w_{m}-s-m \geq 0$ because otherwise the retailer will order an infinite quantity. Such a contract has been widely observed in the retail industry and $m$ is called markdown money.

Another related class of contracts is sales rebates. Suppose that the manufacturer sells to the retailer at a wholesale price $w_{r}$ but as an incentive to generate sales, offers to pay $r$ for each unit sold at regular price. Now, observe that a markdown money contract $\left(w_{m}, m\right)$ with $m<0$ is equivalent to a sales rebate contract with $w_{r}=w_{m}+|m|$ and $r=|m|$. In other words, rather than interpreting $m<0$ as a penalty for not selling, we may see it as a reward for selling. We emphasize that our analysis allows for $m<0$; the only required condition is $w_{m}-s-m \geq 0$ as explained above. When the need arises, we use the terminology positive markdown contracts $(m \geq 0)$ and sales rebates $(m<0)$ to distinguish between the two cases; otherwise, we generally use "markdown money contracts" to refer to both cases.

Under a markdown money contract, the retailer's profit function is $\Pi_{m}^{r}(Q, p)=(p-s-m) E(X \wedge$ $Q)-\left(w_{m}-s-m\right) Q$. Here, the subscript $m$ stands for "markdown money". The RE equilibrium between the retailer and the consumers is derived similarly as before: the retailer's order quantity $Q_{m}$ and retail price $p_{m}$ satisfy $\bar{F}\left(Q_{m}\right)=\frac{w_{m}-s-m}{p_{m}-s-m}$, and $p_{m}=s+(v-s) \bar{F}\left(Q_{m}\right)$.

Next, we show that markdown money contracts can achieve the profit benchmark $\Pi_{q}^{*}$, while splitting total profits arbitrarily between the manufacturer and the retailer. Let $\lambda$ denote the retailer's profit share that the supply chain wishes to realize. Next, let $\lambda^{*}$ denote the retailer's profit share under the wholesale price contract attaining $\Pi_{q}^{*}$, and let $w^{*}$ and $p^{*}$ denote the corresponding wholesale and retail prices. With this additional notation, we have the following proposition.

Proposition 7. Let $\lambda \in[0,1]$. Under the markdown money contract $w_{m}=\left(1-\frac{\lambda}{\lambda^{*}}\right) p^{*}+$ $\frac{\lambda}{\lambda^{*}} w^{*}$ and $m=\left(1-\frac{\lambda}{\lambda^{*}}\right)\left(p^{*}-s\right)$, the optimal profit under quantity commitment $\Pi_{q}^{*}$ is achieved and the retailer's share is $\lambda \Pi_{q}^{*}$.

Markdown money contracts represent an improvement over the wholesale price contracts in 
Section 4.1 because the former can attain the quantity-commitment benchmark $\Pi_{q}^{*}$ while allocating profits arbitrarily. However, with markdown money contracts, the manufacturer needs to verify the number of salvaged units, and this might give rise to additional monitoring costs. Nevertheless, a powerful member in the supply chain may still prefer a profit allocation scheme other than the one resulting from $w_{q}^{*}$ (i.e., the wholesale price contract yielding $\Pi_{q}^{*}$ ). It is well-known in the operations literature that markdown money contracts can coordinate supply chains and allocate total profits arbitrarily. Such a result continues to hold in our model with strategic customers when quantity-commitment is desirable.

In terms of implementation, it is useful to check whether we need a positive markdown money contract or a sales rebate contract. The following proposition provides the answer.

Proposition 8. Suppose we wish to attain the profit benchmark $\Pi_{q}^{*}$ while allocating a fraction $\lambda \in[0,1]$ of it to the retailer. (i) When $\lambda \leq \lambda^{*}$, we can use a positive markdown money contract with $w_{m}=\left(1-\frac{\lambda}{\lambda^{*}}\right) p^{*}+\frac{\lambda}{\lambda^{*}} w^{*} \geq w^{*}$ and $m=\left(1-\frac{\lambda}{\lambda^{*}}\right)\left(p^{*}-s\right)$. (ii) When $\lambda>\lambda^{*}$, we can use a sales rebate contract with $w_{r}=\left(1-\frac{\lambda}{\lambda^{*}}\right) s+\frac{\lambda}{\lambda^{*}} w^{*}>w^{*}$ and $r=\left|1-\frac{\lambda}{\lambda^{*}}\right|\left(p^{*}-s\right)$.

This result indicates that when using markdown money contracts, the wholesale price (whether $w_{m}$ or $w_{r}$ ) is at least as large as the pure wholesale price $w^{*}$ attaining $\Pi_{q}^{*}$. In other words, in return for offering markdown allowances (or sales rebates), manufacturers charge higher wholesale prices. Indeed, it is not surprising that many retailers perceive markdown money as "getting their money back" (see Hurlbut, 2005).

Proposition 8 also reveals that although both positive markdowns and sales rebates can be used to attain the profit benchmark $\Pi_{q}^{*}$, the former allocates a smaller share to the retailer. Specifically, using positive markdowns to attain $\Pi_{q}^{*}$ imposes a profit cap of $\lambda^{*} \Pi_{q}^{*}$ on the retailer, and using sales rebates imposes a profit cap of $\left(1-\lambda^{*}\right) \Pi_{q}^{*}$ on the manufacturer. Therefore, our model suggests that a strong manufacturer (when $\lambda$ is small) should offer positive markdown money, whereas a strong retailer (when $\lambda$ is large) should demand sales rebates. For example, in practice, positive markdowns are often offered by luxury fashion designers; however, whether the division of bargaining power in 
this example agrees with our predictions is an open empirical question.

Nevertheless, positive markdown allowances appear to be the norm in today's retail environment, despite the presence of increasingly dominant retailers. Since strong retailer power is incompatible with the cap on their profits (under positive markdown allowances), our analysis suggests that internal discord may arise. Indeed, the recent controversy over markdown money has sparked several heated arguments between retailers and their suppliers (see Rozhon, 2005). On one hand, retailers are demanding substantial amounts of markdown money from their suppliers and threatening not to place orders for the upcoming season if the suppliers do not pay. On the other hand, suppliers accuse retailers of marking down items more aggressively than necessary and refuse to share their burden of lost margins. From a practical viewpoint, it would be interesting to see whether adopting sales rebates (rather than markdown allowances) would ease this tension in the retail sector.

\section{Achieving Price Commitment in Decentralized Supply Chains}

In this section, we show that decentralized supply chains can attain the price-commitment benchmark profit $\Pi_{p}^{*}$ using buyback contracts. Under these contracts, the manufacturer sells to the retailer at wholesale price $w_{b}$ and agrees to buy back unsold items at $b$ per unit after demand is realized. However, they do not allow an arbitrary division of profits.

\subsection{Buyback contracts}

There are two separate cases to consider. When $b<s$, the retailer would be better off directing excess inventory into his salvage market rather than selling them back to the manufacturer. The buyback option is as good as none, and the $\left(w_{b}, b\right)$ contract reduces to a pure wholesale contract, which has already been studied above. Therefore, our study of buyback contracts focuses on the case where $b \geq s$. In this case, the option of selling excess inventory back to the manufacturer becomes more attractive than marking down the price. Remarkably, this buyback provision eliminates the salvage market, thereby inducing all customers to pay the maximum regular price of $v$. We stress that this is possible only if excess inventory is actually delivered back to the manufacturer (or disposed of). Mere monetary transfers are insufficient because the retailer has to "burn his own 
bridge" in order to convince customers that he is unable to activate his salvage market after all intrasupply-chain transactions have occurred. Like the monitoring costs associated with a markdown money contract, there are also costs for implementing a buyback contract: for example, shipping costs for returns or costs for disposing the unsold products. However, these costs are assumed to be negligible because including them does not generate any additional insights.

Observe that buyback contracts resemble the markdown money contracts studied in Section 4.2. The only difference lies in whether goods are physically returned to the manufacturer. While most studies in the operations literature overlook this difference, we emphasize its importance in achieving price-commitment. In addition, our model highlights two other differences. First, markdown allowances are used to achieve quantity-commitment but buybacks are used to achieve price-commitment. Second, markdown money contracts can allocate profits arbitrarily between supply chain members while buybacks can not.

We now proceed with the analysis. Suppose that a buyback contract $\left(w_{b}, b\right)$ with $b \geq s$ has been established at the outset. In this environment, the RE equilibrium (between the retailer and the strategic customers) dictates that prices (selling price, reservation price, anticipated reservation price) are all $p=r=\xi_{r}=v$ and the anticipated probability of low-price availability is $\xi_{\text {prob }}=0$. Then, the retailer faces the profit function $\Pi_{b}^{r}(Q)=(v-b) E(X \wedge Q)-\left(w_{b}-b\right) Q$ and chooses the quantity $Q_{b}^{r}$ satisfying $\bar{F}\left(Q_{b}^{r}\right)=\left(w_{b}-b\right) /(v-b)$. Here, the subscript $b$ stands for "buyback." We also define $\Pi_{b}^{m}(Q)$ and $\Pi_{b}(Q)=\Pi_{b}^{r}(Q)+\Pi_{b}^{m}(Q)$ as the manufacturer's profits and total supply chain profits (under the buyback contract), as a function of the retailer's order quantity $Q$. These profit functions, respectively, are $\Pi_{b}^{m}(Q)=b E(X \wedge Q)+\left(w_{b}-c-b\right) Q$ and $\Pi_{b}(Q)=v E(X \wedge Q)-c Q$. Total supply chain profit $\Pi_{b}(Q)$ is maximized at $Q_{b}$ satisfying $\bar{F}\left(Q_{b}\right)=c / v$. Observe that total supply chain profits under the buyback contract $\Pi_{b}(Q)$ coincides with the profit function of the centralized system with price-commitment, $\Pi_{p}(Q)$, so their maximizers also coincide. Therefore, if the supply chain can be coordinated to produce and stock the optimal quantity $Q_{b}$, the price-commitment profit benchmark $\Pi_{p}^{*}$ can be attained. The next proposition shows that this can indeed be done, but only for a certain range of profit allocations. 
Proposition 9. Let $\lambda \in\left[0,1-\frac{s}{v}\right]$. Under the buyback contract $w_{b}=\lambda c+(1-\lambda) v$, and $b=$ $(1-\lambda) v$, the $R E$ equilibrium outcome attains the price-commitment profit benchmark $\Pi_{p}^{*}$ for the system. Further, the retailer's profit is $\lambda \Pi_{p}^{*}$ and the manufacturer's profit is $(1-\lambda) \Pi_{p}^{*}$.

Our results identify a new role that buyback contracts play when customers are strategic: they serve as a commitment device. The ability to commit to strategic customers, combined with the ability to coordinate on mutually beneficial actions, allows supply chains to attain the profit levels of a centralized system with price-commitment. This may not even be an alternative when a centralized seller operates in isolation. Industry evidence seems to be consistent with the above analysis. For example, buyback or return policies are widely used in the book industry. Instead of marking down prices, major retailers such as Barnes \& Noble return the unsold books to their publishers when the selling season ends. The returned copies are then sold to companies specializing in bargain books, or, books that cannot be sold are simply pulped for a total loss. There is an ongoing debate in the book industry over whether returns should be eliminated: while some retailers claim that they are willing to mark down books and sell them on spot, most publishers are leery of the change (see Trachtenberg, 2005). In fact, one major concern is that readers may learn to wait until books are cheaper. We suspect that the book industry, in spite of losses due to returns, may still be using such a practice as a price-commitment device in order to extract higher profits.

As Proposition 9 illustrates, buyback contracts impose an upper bound of $1-\frac{s}{v}$ on the retailer's profit share. Typically, the ability to allocate profits arbitrarily between parties is an important criterion in evaluating different contractual formats. The possibility of arbitrary profit allocations separates the coordination process from the allocation process: the supply chain can concentrate on maximizing the size of the pie before negotiating over individual shares. In the current case, the upper bound on retailer share may create problems, especially when the retailer is powerful relative to the manufacturer. In an era with retailers becoming increasingly dominant (see Messinger and Narasimhan, 1995 \& Bloom and Perry, 2001), it has become difficult to use buyback contracts as a price-commitment device when retailers actively negotiate against the profit cap imposed on them 
Su and Zhang: Strategic customer behavior, commitment, and supply chain performance

by optimal buyback agreements. Yet, ironically, it is precisely these profit caps (due to condition $b \geq s)$ that make buybacks effective in providing price-commitment. The inevitable consequence is that attaining price-commitment via buyback arrangements may no longer be feasible.

Another limitation of using buyback contracts to achieve price-commitment is renegotiation. Buyback contracts are ex-ante agreements to limit ex-post total profits to zero, but they are not renegotiation-proof as long as there exists ex-post opportunities to reap positive profits. When the buyback contract is prone to renegotiation, it can no longer provide credible price-commitment. Recently there have been several studies looking at the issue of renegotiation in supply chains, for instance, Iyer and Villa-Boas (2003) \& Plambeck and Taylor (2004).

Finally, we close this section with the observation that more attractive alternatives may exist. So far, we have lauded the use of the buyback contract because of its ability to achieve pricecommitment. Now, consider the following alternative. Rather than negotiating a buyback contract with the upstream manufacturer, the retailer contracts with customers instead. Specifically, the retailer may mitigate consumers' price risk by offering to reimburse the difference if prices fall in the future. Under this agreement, consumers are willing to pay $v$ at the outset and the retailer should mark prices down to $s$ if and only if $x / Q \leq s / v$ (i.e., the proportion of inventory $Q$ sold is less than $s / v)$. It can be shown that supply chain profits will be $v E(X \wedge Q)-c Q+\int_{0}^{s Q / v}(s Q-v x) d F(x)$. The last term reflects incremental profits from the opportunity to make an ex-post markdown decision, which is always better than making an ex-ante commitment not to mark down. Indeed, this profit function is always greater than the price-commitment profit function $\Pi_{p}(Q)$; similar comparisons have been made by Png (1991). Therefore, although buybacks can be designed to provide pricecommitment, there exists alternatives (e.g., price protection arrangements) that perform better.

\section{Extensions and discussion 6.1. Heterogeneous valuations}

In the preceding analysis, we have assumed that all customers place the same valuation $v$ on the product. Now, suppose that the customer pool is heterogeneous and indexed by $\theta \in[0,1]$. For each type $\theta$, there is an associated valuation $v_{\theta}$, which is increasing in $\theta$. That is, a higher type is 
associated with a higher valuation. Assume that the range of valuations is $\left[v_{0}, v_{1}\right]$ and $c<v_{0}$. Let $G(\theta)$ denote the proportion of customers of type $\theta$ and below (i.e., customers with valuations not exceeding $v_{\theta}$ ). As before, the total demand $X$ follows distribution $F$. Within this more complex environment, how would our earlier techniques and results change?

In the appendix, we extend the RE equilibrium concept to accommodate heterogeneous customers and present techniques for deriving the equilibrium. In particular, Lemma EC.1 in the appendix proves that in a $\mathrm{RE}$ equilibrium, there exists a threshold type $\theta_{p}$ (correponding to the seller's price $p$ ) such that customers of type $\theta_{p}$ and above will buy immdediately while the rest of customers will wait. Therefore, by choosing the price $p$, the seller is essentially choosing the segment of customers who will buy immediately. In this way, apart from quantity decisions, the seller also faces the task of finding the optimal price $p^{*}$ that yields maximum profit. Notice how this is similar to the homogeneous customer case: with homogeneous customers, the optimal price must be equal to customers' reservation price, which is the same for all customers; while with heterogeneous customers, the buyer faces a continuous range of reservation prices and she can choose the marginal type who will buy immediately.

Next we describe the seller's problem. For a chosen $p$, the marginal customer type $\theta_{p}$ satisfies

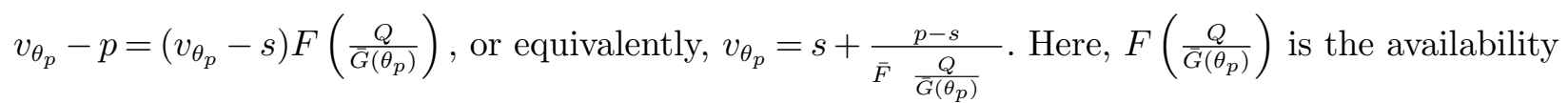
probability in the salvage market given that the seller has chosen $Q$ and all customers above $\theta_{p}$ will purchase immediately. That is, type $\theta_{p}$ customers are indifferent between buying now and waiting. Note that in equilibrium, $Q$ should maximize the seller's expected profit $\Pi(Q, p)=(p-$ $\left.s) E\left[\left(\bar{G}\left(\theta_{p}\right) X\right) \wedge Q\right)\right]-(c-s) Q$. Therefore, we have $\bar{F}\left(\frac{Q}{\bar{G}\left(\theta_{p}\right)}\right)=\frac{c-s}{p-s}$. Together, we know that the marginal valuation $v_{\theta_{p}}$ is given by $v_{\theta_{p}}=s+\frac{(p-s)^{2}}{c-s}$. Thus, the seller's pricing problem can be written as $\left.\max _{p} \Pi(p)=(p-s) E\left[\left(\bar{G}\left(\theta_{p}\right) X\right) \wedge Q\right)\right]-(c-s) Q$, where both $Q$ and $\theta_{p}$ are functions of $p$.

Suppose the seller wishes to sell to customers with types $\theta$ and above (or customers with valuation $v_{\theta}$ or above), then she may do so using the RE equilibrium price $p_{c}$ and quantity $Q_{c}$ derived from the analysis of a homogenous market with valuation $v_{\theta}$ and size $\bar{G}(\theta) X$. That is, for any price $p$ chosen by the seller in a heterogeneous market, one may construct a homogeneous market 
which yields the same outcome for the seller. In this sense, one may expect that the results that hold for each homogeneous market should remain largely unchanged in this heterogeneous market. However, the model with heterogeneous customer valuations is less tractable due to the presence of two distribution functions $F$ (for market size) and $G$ (for customer valuations). Nonetheless, in the numerical examples presented in the online appendix, we find that the key insight from this paper is still true: with strategic customers, double marginalization may improve supply chain efficiency. Therefore, simplified settings with homogenous customers, as analyzed earlier, are representative of the strategic interactions that take place in a heterogeneous world.

\subsection{Discount factor}

Suppose that consumers use a discount factor of $\delta \in[0,1]$ on end-of-season payoffs. Then, given that the anticipated probability of availability is $\xi_{\text {prob }}$, the consumer's expected surplus from waiting for a sale is now $\delta \xi_{\text {prob }}(v-s)$ instead of $\xi_{\text {prob }}(v-s)$ as before. This implies that the consumer's reservation price would be $r=v-\delta \xi_{\text {prob }}(v-s)$.

In the centralized case, the RE equilibrium quantity $Q_{\delta}$ is now characterized by $\delta \bar{F}^{2}\left(Q_{\delta}\right)+(1-$ $\delta) \bar{F}\left(Q_{\delta}\right)=\frac{c-s}{v-s}$. Observe that when $\delta=1$, we have $\bar{F}\left(Q_{\delta}\right)=\sqrt{\frac{c-s}{v-s}}$, which agrees with Proposition 1. On the other hand, when $\delta=0$, we have $\bar{F}\left(Q_{\delta}\right)=\frac{c-s}{v-s}$, which is intuitive since setting $\delta=0$ eliminates the viability of the salvage market, so consumers never wait for the sale and we return to the standard newsvendor model. As $\delta$ increases from 0 to 1, consumers become more patient and the effect of strategic behavior becomes more salient: equilibrium price and quantity both decrease, as is necessary to encourage start-of-season purchases, and this leads to lower seller profits.

In the decentralized case, time discounting also does not affect the qualitative nature of our results. Contractual agreements can still be used to attain the price-commitment and quantitycommitment outcomes. However, since $\Pi_{p}^{*}$ is independent of $\delta$ whereas $\Pi_{q}^{*}$ decreases as $\delta$ increases, increased consumer patience (higher $\delta$ ) creates a bias in favor of price-commitment.

There are at least two alternative interpretations of the discount factor. First, the same construction above can be used to capture risk aversion. Some consumers are willing to pay a risk premium 
on end-of-season surplus as it involves the risk of stockouts, so they adopt a discount factor of $\delta<1$. On the other hand, risk-seeking preferences would require $\delta>1$. The second alternative interpretation of the discount factor involves estimation errors. If consumers consistently underestimate availability, we can model this using $\delta<1$; analogously, we can use $\delta>1$ to represent over-estimation.

\subsection{Customer arrival process}

Our basic model is an extension of the newsvendor setup and we use a single random variable to capture one-shot demand. In reality, it would be more natural to assume that customers arrive over time. Since our focus is on supply chain contracting issues, we abstract from dynamic pricing and continue to assume that the seller may charge at most two different prices: a regular season price, and a markdown price after all customers have arrived. As before, each customer's buy-or-wait decision depends on the comparison between the product price and the customer's reservation price. Since both these are independent of the sequence of customer arrivals, the equilibrium outcome of this game as well as our earlier results remain unchanged.

Further, suppose that customers have discounted valuations, i.e., a later arrival is associated with a lower valuation for the product. Assume the range of customer valuations is $\left[v_{0}, v_{1}\right]$, i.e., the first arrival has a valuation $v_{1}$ and the last arrival has a valuation $v_{0}$. Then we go back to the heterogeneous model discussed in Section 6.1: arrival time can be used to index the customers $(\theta$ is the arrival time) and the corresponding distribution function $G$ can be constructed using the dynamic arrival process. From the discussion in Section 6.1, our main insights remain unchanged.

\subsection{Endogenous salvage price}

So far we have assumed a constant salvage value $s$. This enables us to study the impact of strategic customer behavior on the classic newsvendor model, as well as the impact on supply chain contracting. However, more generally, there may be price effects on the salvage market. To capture price effects on the salvage market, suppose that the salvage price $s$ is a decreasing function of the number of left-over units $Q_{l}$, denoted by $s\left(Q_{l}\right)$. As a benchmark for comparison, we consider 
$s=s(0)<c$ in our basic model. Then with endogenous salvage value $s\left(Q_{l}\right)$, increasing the seller's quantity $Q$ has a two-fold effect: first, it will increase product availability in the salvage market; second, it will decrease the salvage price $s\left(Q_{l}\right)$ since $Q_{l}$ will be stochastically larger. Note that only the first effect exists in the basic model with $s=s(0)$. Thus in the model with endogenous salvage value $s\left(Q_{l}\right)$, customers would have more incentive to wait, compared to in the basic model with a constant salvage price $s(0)$. As a result, the seller's optimal quantity would be even lower. This implies that the effect of strategic customer behavior will be stronger when we consider price effects on the salvage market.

\subsection{Bargain-hunters and price-takers}

So far, our analysis assumes that all customers are strategic bargain-hunters and may wait for endof-season sales. In reality, there may be a segment of price-taking customers who do not consider the possibility of waiting for a sale. They either purchase the product at regular price (if it is below their valuation) or leave the market; we refer to them as myopic. To improve realism, we may consider both strategic and myopic customers. Let $\phi$ and $\bar{\phi}=1-\phi$ denote the fraction of strategic and myopic consumers, and we continue to assume that all consumers have valuation $v$.

The introduction of myopic consumers presents sellers with a choice over two alternatives. The first alternative, as before, is to choose a regular price at which all consumers (both strategic and myopic) are willing to buy; this brings us back to the previous analysis. The second alternative is to price the product at $v$ and sell only to myopic consumers at this price; in this case, the demand is effectively $\bar{\phi} X$ and this becomes a standard newsvendor problem. As long as the fraction $\phi$ of strategic consumers is large enough, the first alternative is preferred and our earlier model applies.

\section{Conclusion}

Strategic consumer behavior has largely been overlooked in the supply chain management literature. This paper attempts to fill this gap. Our basic premise is that consumers look ahead and plan purchases with future opportunities in mind. By doing so, consumers force firms to compete against their own future selves. This can be alleviated if firms can somehow "promise" to consumers that 
future purchase opportunities will be unattractive: either prices will remain high, or availability will be limited. However, in most situations, such commitments are not credible because firms will be better off not fulfilling these commitments at the time they become due.

Decentralized supply chains, on the other hand, can make credible commitments to consumers in an indirect way. Through appropriate contractual mechanisms, supply chain parties can structure the incentive system such that it will indeed be in the best interests of at least one party to maintain high prices or low availability in the future. Indirectly, these outcomes discourage strategic behavior and increase supply chain profits. While decentralization has generally been associated with coordination problems, we present the contrasting view that disparate interests within a supply chain can actually be used to realize improved outcomes. In fact, decentralized supply chains sometimes perform strictly better than their centralized counterparts.

Future research can extend our line of inquiry in several directions. First, a more comprehensive study comparing supply chain performance under various contractual formats in the presence of strategic customer behavior could be an interesting research direction. Second, many operational strategies (e.g., quick response and collaborative forecasting) are designed to improve service levels by creating more flexible replenishment opportunities or improving the demand forecast. However, our analysis suggests that improving service levels may hurt firms' profits because this places customers at a better position to game against them. It would be interesting to investigate how the introduction of customer behavior affects the incentives for adopting these operational strategies. Third, a similar analysis can be conducted in a setting with horizontal competition. In this case, how do strategic consumers influence the competitive landscape? In general, we believe that strategic consumer behavior is a fruitful research topic. Beyond supply chain settings, similar issues also arise in revenue management and in service contexts. We hope that the framework in this paper, based on the rational expectations hypothesis, can be applied to other areas in operations management.

\section{References}

Arya, A., B. Mittendorf. 2005. Benefits of channel discord in the sale of durable goods. Mktg. Sc., to appear. 
Aviv, Y., A. Pazgal. 2005. Optimal pricing of seasonal products in the presence of forward-looking consumers. Working paper.

Bloom, P., V. Perry. 2001. Retailer power and supplier welfare. J. Retailing. 77: 379-396.

Bulow, J.I. 1982. Durable-goods monopolists. J. Pol. Econ. 90(2): 314-332.

Bulow, J.I., P.D. Klemperer. 1996. Auctions vs. negotiations. Amer. Econ. Rev. 86(1): 180-194.

Byrnes, N., W. Zellner. 2004. Playing the discount game. Bus. Week. Dec 13.

Cachon, G.P. 2003. Supply chain coordination with contracts. Handbooks in OREMS. Graves, de Kok, eds.

Cachon, G.P. 2004. The allocation of inventory risk in a supply chain: push, pull, and advance-purchase discount contracts. Mgt. Sc. . 50(2): 222-238.

Cachon, G.P., A.G. Kok. 2004. How to (and how not to) estimate the salvage value in the newsvendor model. Forthcoming in MESOM.

Caldentey, R., G. Vulcano. 2004. Online auction and list price revenue management. Mgmt. Sci. Forthcoming.

Coase, R.H. 1972. Durability and monopoly. J. Law E⿱ Econ. 15(1): 143-149.

Dana, J.D., N.C. Petruzzi. 2001. The newsvendor model with endogenous demand. Mgt. Sc. 47(11): 1488-97.

Desai, P., O. Koenigsberg, D. Purohit. 2004. Strategic decentralization and channel coordination. Quant. Mktg. \& Econ. 2: 5-22.

Elmalghraby, W., A.Gulcu, P. Keskinocak. 2004. Optimal markdown mechanisms in the presence of rational customers with multi-unit demands. Working paper.

Ferdows, K., M.A. Lewis, J.A.D. Machuca. 2005. Zara's secret for fast fashion.

Gallien, J. 2005. Dynamic mechanism design for online commerce. Working paper.

Gallien, J., S. Gupta. 2005. Temporary permanent buyout prices in online auctions. Mgmt. Sci. To appear.

Ho, T.-H., C.S. Tang, D.R. Bell. 1998. Rational shopping behavior and the option value of variable pricing. Mgt. Sc. 44(12): S145-S160.

Hurlbut, T. 2005. The markdown blues, revisited. Inc.com. March.

Jacobson, R., C. Obermiller. 1990. The formation of expected future prices: a reference price for forwardlooking consumers. J. Consumer Res. 16: 420-432.

Kadet, A. 2004. The price is right. Smart Money. December: 90-94. 
Khouja, M. 1999. The single-period (newsvendor) problem: literature review and suggestions for future research. Omega. 27: 537-553.

Krishna, A. 2004. The impact of dealing patterns on purchase behavior. Mktg. Sc. 13(4): 351-373.

Krishna, A., I. Currim, R. Shoemaker. 1991. Consumer perceptions of promotion activity. J. Mktg. 55: 4-16.

Lariviere, M., E. Porteus. 2001. Selling to the newsvendor: an analysis of price-only contracts. MESSOM. 3(4): 293-305.

Messinger, P., C. Narasimhan. 1995. Has power shifted in the grocery channel. Mktg. Sc. 14(2): 189-223.

Muth, J.F. 1961. Rational Expectations and the Theory of Price Movements. Econometrica 29: 315-335.

Netessine, S., F. Zhang. 2005. Positive vs. negative externalities in inventory management: implications for supply chain design. MESOM. 7(1): 58-73.

Petruzzi, N., M. Dada. 1999. Pricing and the newsvendor problem: a review extensions. Oper. Res. 47: 183-94.

Png, I.P. 1991. Most-favored-customer protection vs price discrimination over time. J. Pol. Econ. 99:1011-28.

Rozhon, T. 2005. First the markdown, then the showdown. New York Times. February 25: C1.

Silver, E.A., D.F. Pyke, R.P. Peterson. 1998. Inventory management and production planning scheduling. 3rd edition. New York: John Wile.

Sliwa, C. 2003. Retailers explore price optimization. ComputerWorld. Jan. 20.

$\mathrm{Su}$, X. 2005. Inter-temporal pricing with strategic customer behavior. Mgt. Sci. Forthcoming.

Trachtenberg, J.A. 2005. Shelf life: quest for best seller creates a pileup of returned books. WSJ. Jun 3.

van Ryzin, G., Q. Liu. 2005. Strategic capacity rationing to induce early purchases. Working paper.

Vulcano, G., G. van Ryzin, C. Maglaras. 2002. Optimal dynamic auctions for revenue management. Mgt. Sc. 48(11): 1388-1407.

Wingfield, N., R.A. Guth. 2005. Why shortages of hot gifts endure as a Christmas ritual. WSJ. Dec 2.

Yin, R., C.S. Tang. 2006. The implications of customer purchasing behavior and in-store display formats. Working paper.

Yu, M., R. Kapuscinski, H.-S. Ahn. 2006. Advance selling with limited capacity. Working paper.

Zhou, Y.P., M. Fan, M. Cho. 2005. On the threshold purchasing behavior of customers facing dynamically priced perishable products. Working paper. 
This page is intentionally blank. Proper e-companion title page, with INFORMS branding and exact metadata of the main paper, will be produced by the INFORMS office when the issue is being assembled. 


\section{Proofs of Statements}

\section{Supplementary Appendix A: Proofs}

Proof of Proposition 1 The RE equilibrium conditions

$$
\begin{aligned}
p & =v-(v-s) F(Q), \\
Q & =\arg \max _{Q} \Pi(Q, p),
\end{aligned}
$$

reduce to

$$
\begin{aligned}
p & =s+(v-s) \bar{F}(Q), \\
\bar{F}(Q) & =\frac{c-s}{p-s},
\end{aligned}
$$

respectively. Solving these equations yields the desired results.

Proof of Lemma 1 The first-order-condition $\Pi_{q}^{\prime}(Q)=0$ yields

$$
\frac{c-s}{\bar{F}(Q)}+(v-s) \frac{f(Q)}{\bar{F}(Q)} E(X \wedge Q)=(v-s) \bar{F}(Q)
$$

The left-hand-side is increasing (because $F$ has an increasing failure rate), and the right-handside is decreasing in $Q$, so the first-order-condition has a unique solution. Further, we know that $\Pi_{q}^{\prime}(0)=v-c>0$ and $\lim _{Q \rightarrow \infty} \Pi_{q}^{\prime}(Q)=-(c-s)<0$. Therefore, $\Pi_{q}(Q)$ is quasi-concave and has a unique maximizer.

Proof of Proposition 2 (i) The derivative of $\Pi_{q}(Q)$ at $Q=Q_{c}$ is:

$$
\begin{aligned}
\Pi_{q}^{\prime}\left(Q_{c}\right) & =(v-s) \bar{F}^{2}\left(Q_{c}\right)-(c-s)-(v-s) E\left(X \wedge Q_{c}\right) f\left(Q_{c}\right) \\
& =-(v-s) E\left(X \wedge Q_{c}\right) f\left(Q_{c}\right) \\
& <0,
\end{aligned}
$$

where the second equality follows from $(v-s) \bar{F}^{2}(Q)-(c-s)=0$. From the previous lemma we know that $\Pi_{q}(Q)$ is increasing first and then decreasing in $Q$. Hence there must be $Q_{q}^{*}<Q_{c}$ and $\Pi_{q}^{*} \geq \Pi_{c}$. 
(ii) We begin by varying $c \in[s, v]$ while holding $s$ and $v$ fixed. The seller's profit in the RE equilibrium is

$$
\begin{aligned}
\Pi_{c} & =\left(p_{c}-s\right) E\left(X \wedge Q_{c}\right)-(c-s) Q_{c} \\
& =\sqrt{(v-s)(c-s)} E\left(X \wedge Q_{c}\right)-(c-s) Q_{c} .
\end{aligned}
$$

By the Envelope Theorem, the derivative of $\Pi_{c}$ with respect to $c$ can be written as

$$
\begin{aligned}
\frac{d \Pi_{c}}{d c} & =\frac{1}{2} \sqrt{\frac{v-s}{c-s}} E\left(X \wedge Q_{c}\right)-Q_{c} \\
& =\frac{1}{2 \bar{F}\left(Q_{c}\right)} E\left(X \wedge Q_{c}\right)-Q_{c} .
\end{aligned}
$$

Taking derivative again with respect to $Q_{c}$ gives

$$
\frac{d}{d Q_{c}}\left(\frac{d \Pi_{c}}{d c}\right)=\frac{f\left(Q_{c}\right)}{2\left(\bar{F}\left(Q_{c}\right)\right)^{2}} E\left(X \wedge Q_{c}\right)-\frac{1}{2} .
$$

It is clear that $\frac{f\left(Q_{c}\right)}{2 \bar{F}\left(Q_{c}\right)} E\left(X \wedge Q_{c}\right)$ is increasing in $Q_{c}$ because $F$ has an increasing failure rate. So there exists $\hat{Q}_{c}$ such that $\frac{d}{d Q_{c}}\left(\frac{d \Pi_{c}}{d c}\right) \leq 0$ for $Q_{c} \leq \hat{Q}_{c}$ and $\frac{d}{d Q_{c}}\left(\frac{d \Pi_{c}}{d c}\right) \geq 0$ for $Q_{c} \geq \hat{Q}_{c}$. Since $Q_{c}$ is monotonically decreasing in $c$, we know there exists $\tilde{c}$ such that $\Pi_{c}$ is concave in $c$ for $c \leq \tilde{c}$ and $\Pi_{c}$ is convex in $c$ for $c \geq \tilde{c}$.

Next we show that $\Pi_{q}^{*}$ is convex and decreasing in $c$. Since

$$
\begin{aligned}
\Pi_{q}(Q) & =(p(Q)-s) E(X \wedge Q)-(c-s) Q \\
& =(v-s) \bar{F}(Q) E(X \wedge Q)-(c-s) Q
\end{aligned}
$$

applying the Envelope Theorem gives

$$
\frac{d \Pi_{q}^{*}}{d c}=-Q_{q}^{*} \text { and } \frac{d^{2} \Pi_{q}^{*}}{d c^{2}}=-\frac{d Q_{q}^{*}}{d c}>0
$$

where the inequality follows from the fact that $Q_{q}^{*}$ is decreasing in $c$. Note that $\left.\Pi_{q}^{*}\right|_{c=s}>0$ while $\left.\Pi_{c}\right|_{c=s}=0$, so the existence of $c_{l}$ follows.

To show the existence of $c_{h}$, we first write down the first-order conditions for maximizing $\Pi_{q}(Q)$ and $\Pi_{c}(Q)$, respectively. The former is

$$
\frac{c-s}{v-s}+f(Q) E(X \wedge Q)=\bar{F}^{2}(Q),
$$


and the latter is $\bar{F}(Q)=\sqrt{\frac{c-s}{v-s}}$, or equivalently,

$$
\frac{c-s}{v-s}=\bar{F}^{2}(Q)
$$

These first-order conditions yield

$$
\begin{aligned}
\frac{d Q_{q}^{*}}{d c} & =-\frac{1}{(v-s)\left[f^{\prime}\left(Q_{q}^{*}\right) E\left(X \wedge Q_{q}^{*}\right)+3 f\left(Q_{q}^{*}\right) \bar{F}\left(Q_{q}^{*}\right)\right]}, \\
\frac{d Q_{c}}{d c} & =-\frac{1}{2(v-s) f\left(Q_{c}\right) \bar{F}\left(Q_{c}\right)} .
\end{aligned}
$$

Let us define $h_{q}(c) \equiv \frac{d}{d c} \Pi_{q}^{*}, h_{c}(c) \equiv \frac{d}{d c} \Pi_{c}$, and $g(c) \equiv h_{q}(c)-h_{c}(c)$. Then we have

$$
g(c)=-Q_{q}^{*}-\frac{1}{2 \bar{F}\left(Q_{c}\right)} E\left(X \wedge Q_{c}\right)+Q_{c}
$$

Since $\left.Q_{q}^{*}\right|_{c=v}=\left.Q_{c}\right|_{c=v}=0$ it can be shown that

$$
g^{\prime}(v)=\left[\frac{\partial h_{q}}{\partial Q_{q}^{*}} \frac{d Q_{q}^{*}}{d c}-\frac{\partial h_{c}}{\partial Q_{c}} \frac{d Q_{c}}{d c}\right]_{c=v}=\frac{1}{12(v-s) f(0)}>0
$$

Note that $\left.\Pi_{q}^{*}\right|_{c=v}=\left.\Pi_{c}\right|_{c=v}=0$ and $h_{q}(v)=h_{c}(v)=0$. Together we know that there exists a $c_{h}$ such that $\Pi_{q}^{*}-\Pi_{c}$ is decreasing in $c$ for $c \geq c_{h}$ (if $c_{h}<c_{l}$, then set $\left.c_{h}=c_{l}\right)$.

(iii) First we prove the existence of $v_{l}$. Similar to the proof of (ii), we derive

$$
\begin{aligned}
\frac{d Q_{q}^{*}}{d v} & =\frac{c-s}{(v-s)^{2}\left[f^{\prime}\left(Q_{q}^{*}\right) E\left(X \wedge Q_{q}^{*}\right)+3 f\left(Q_{q}^{*}\right) \bar{F}\left(Q_{q}^{*}\right)\right]}, \\
\frac{d Q_{c}}{d v} & =\frac{\bar{F}\left(Q_{c}\right)}{2(v-s) f\left(Q_{c}\right)} .
\end{aligned}
$$

Define $h_{q}(v) \equiv \frac{d}{d v} \Pi_{q}^{*}, h_{c}(v) \equiv \frac{d}{d v} \Pi_{c}$, and $g(v) \equiv h_{q}(v)-h_{c}(v)$. Applying the Envelope Theorem yields

$$
\begin{aligned}
h_{q}(v) & =\bar{F}\left(Q_{q}^{*}\right) E\left(X \wedge Q_{q}^{*}\right), \\
h_{c}(v) & =\frac{1}{2} \bar{F}\left(Q_{c}\right) E\left(X \wedge Q_{c}\right), \\
g(v) & =\bar{F}\left(Q_{q}^{*}\right) E\left(X \wedge Q_{q}^{*}\right)-\frac{1}{2} \bar{F}\left(Q_{c}\right) E\left(X \wedge Q_{c}\right) .
\end{aligned}
$$

Since $\left.Q_{q}^{*}\right|_{v=c}=\left.Q_{c}\right|_{v=c}=0$, it can be shown that

$$
g^{\prime}(c)=\left[\frac{\partial h_{q}}{\partial Q_{q}^{*}} \frac{d Q_{q}^{*}}{d v}-\frac{\partial h_{c}}{\partial Q_{c}} \frac{d Q_{c}}{d v}\right]_{v=c}=\frac{1}{12(c-s) f(0)}>0 .
$$


Note that $\left.\Pi_{q}^{*}\right|_{v=c}=\left.\Pi_{c}\right|_{v=c}=0$ and $h_{q}(c)=h_{c}(c)=0$. Therefore, there exists $v_{l}$ such that $\Pi_{q}^{*}-\Pi_{c}$ is increasing in $v$ for $v \leq v_{l}$.

Next we prove the existence of $v_{h}$. From the first-order conditions (EC.3) and (EC.4), we know that as $v \rightarrow \infty$, there is $Q_{q}^{*} \rightarrow \hat{Q}$ where $\hat{Q}$ is the unique solution to

$$
f(Q) E(X \wedge Q)=\bar{F}^{2}(Q)
$$

and $Q_{c} \rightarrow \infty$ (or the upper bound of the support of $F$ ). Therefore, as $v \rightarrow \infty$, in

$$
\frac{d \Pi_{q}^{*}}{d v}-\frac{d \Pi_{c}}{d v}=\bar{F}\left(Q_{q}^{*}\right) E\left(X \wedge Q_{q}^{*}\right)-\frac{1}{2} \bar{F}\left(Q_{c}\right) E\left(X \wedge Q_{c}\right),
$$

the first term approaches a constant $\bar{F}(\hat{Q}) E(X \wedge \hat{Q})$ while the second term goes to zero since $\bar{F}\left(Q_{c}\right) \rightarrow 0$ and $E\left(X \wedge Q_{c}\right)$ is bounded by $E(X)$. This shows the existence of $v_{h}$ such that $\Pi_{q}^{*}-\Pi_{c}$ is increasing in $v$ for $v \geq v_{h}$. (This proof shows an interesting point that the derivative of $\Pi_{q}^{*}$ approaches a constant while the derivative of $\Pi_{c}$ approaches zero as $v \rightarrow \infty$.)

Proof of Proposition 3 The proof is similar to that of Proposition 2 and omitted.

Proof of Proposition 4 The proof is similar to that of Proposition 2 and omitted.

Proof of Lemma 2 Consider the equilibrium profits $\Pi_{w}^{r}(Q)$ and $\Pi_{w}^{m}(Q)$ as a function of equilibrium quantities $Q$. Denote the maximizers of these functions $Q_{w}^{r} \in \arg \max _{Q} \Pi_{w}^{r}(Q)$ and $Q_{w}^{m} \in$ $\arg \max _{Q} \Pi_{w}^{m}(Q)$. It suffices to show that (i) $Q_{w}^{r}$ and $Q_{w}^{m}$ are unique, and (ii) $Q_{w}^{m}<Q_{q}^{*}<Q_{w}^{r}$.

(i) Taking derivative of $\Pi_{w}^{r}(Q)$ gives

$$
\frac{d}{d Q} \Pi_{w}^{r}(Q)=(v-s) f(Q)[-E(X \wedge Q)+2 Q \bar{F}(Q)]
$$

Let

$$
g(Q)=-E(X \wedge Q)+2 Q \bar{F}(Q)=-\int_{0}^{Q} x f(x) d x+Q \bar{F}(Q)
$$

then

$$
g^{\prime}(Q)=\bar{F}(Q)-2 Q f(Q)
$$

Since $F$ has an increasing failure rate, we know $g^{\prime}(Q)$ starts at $g^{\prime}(0)=1$ and then decreases to the negative domain. Thus, $g(Q)$ starts at $g(0)=0$, increases first, and then decreases to the negative 
domain. Let $Q_{w}^{r}$ be the unique solution to $g(Q)=0$, then $\Pi_{w}^{r}(Q)$ is increasing for $Q<Q_{w}^{r}$ and decreasing for $Q>Q_{w}^{r}$. That is, $\Pi_{w}^{r}(Q)$ is quasi-concave and has a unique maximizer.

The proof for $\Pi_{w}^{m}(Q)$ is similar and omitted.

(ii) Consider the first-order conditions for $Q_{w}^{r}, Q_{w}^{m}$, and $Q_{q}^{*}$ :

$$
\begin{aligned}
& Q_{w}^{r}: \frac{d}{d Q} \Pi_{w}^{r}(Q)=(v-s) f(Q)[E(X \wedge Q)-2 Q \bar{F}(Q)]=0, \\
& Q_{w}^{m}: \frac{d}{d Q} \Pi_{w}^{m}(Q)=(v-s) \bar{F}^{2}(Q)-(c-s)-(v-s) 2 Q \bar{F}(Q) f(Q)=0, \\
& Q_{q}^{*}: \frac{d}{d Q} \Pi_{q}(Q)=(v-s) \bar{F}^{2}(Q)-(c-s)-(v-s) E(X \wedge Q) f(Q)=0 .
\end{aligned}
$$

Since $E\left(X \wedge Q_{w}^{r}\right)=2 Q_{w}^{r} \bar{F}\left(Q_{w}^{r}\right)$ and $\Pi_{w}^{r}(Q)$ is quasi-concave, we have $\frac{d}{d Q} \Pi_{w}^{m}(Q) \leq \frac{d}{d Q} \Pi_{q}(Q)$ for $Q<Q_{w}^{r}$ and the opposite holds for $Q>Q_{w}^{r}$. Therefore, the only possible orderings for $Q_{w}^{r}, Q_{w}^{m}, Q_{q}^{*}$ are $Q_{w}^{r}<Q_{q}^{*}<Q_{w}^{m}$ and $Q_{w}^{m}<Q_{q}^{*}<Q_{w}^{r}$.

Next we show $Q_{q}^{*}<Q_{w}^{r}$. The retailer's optimal quantity $Q_{w}^{r}$ is given by $E\left(X \wedge Q_{w}^{r}\right)=2 Q_{w}^{r} \bar{F}\left(Q_{w}^{r}\right)$ and is determined only by the distribution function. Define $\beta \equiv \frac{c-s}{v-s}(0<\beta<1)$. Then, the firstorder condition for $Q_{q}^{*}$ can be written as

$$
\beta+f(Q) E(X \wedge Q)=\bar{F}^{2}(Q)
$$

If $\beta+f\left(Q_{w}^{r}\right) E\left(X \wedge Q_{w}^{r}\right)>\bar{F}^{2}\left(Q_{w}^{r}\right)$, then we know $Q_{q}^{*}<Q_{w}^{r}$. Since $\beta>0$, it suffices to show $f\left(Q_{w}^{r}\right) E\left(X \wedge Q_{w}^{r}\right)>\bar{F}^{2}\left(Q_{w}^{r}\right)$. Plugging $E\left(X \wedge Q_{w}^{r}\right)=2 Q_{w}^{r} \bar{F}\left(Q_{w}^{r}\right)$ into the inequality, we only need to show

$$
\bar{F}\left(Q_{w}^{r}\right)-2 Q_{w}^{r} f\left(Q_{w}^{r}\right)<0
$$

Recall from (i) that $g^{\prime}(Q)=\bar{F}(Q)-2 Q f(Q)=0$ has a unique solution. Let $\hat{Q}$ be this solution. In addition, $Q_{w}^{r}$ is the unique solution to $g(Q)=0$. This implies that $\hat{Q}<Q_{w}^{r}$, so we have

$$
g^{\prime}\left(Q_{w}^{r}\right)=\bar{F}\left(Q_{w}^{r}\right)-2 Q_{w}^{r} f\left(Q_{w}^{r}\right)<g^{\prime}(\hat{Q})=0
$$

The desired result follows. 
Proof of Proposition 7 First, recall that the equilibrium quantity $Q_{q}^{*}$ and price $p^{*}$ in the coordinating wholesale price contract satisfy

$$
\begin{aligned}
\bar{F}\left(Q_{q}^{*}\right) & =\frac{w^{*}-s}{p^{*}-s} \\
p^{*} & =s+(v-s) \bar{F}\left(Q_{q}^{*}\right) .
\end{aligned}
$$

Now, consider the markdown money contract with parameters $w_{m}$ and $m$ satisfying

$$
\begin{gathered}
w_{m}-s-m=\chi\left(w^{*}-s\right), \\
p^{*}-s-m=\chi\left(p^{*}-s\right),
\end{gathered}
$$

for some $\chi>0$. Recall that the RE equilibrium conditions under this contract are

$$
\begin{aligned}
\bar{F}\left(Q_{m}\right) & =\frac{w_{m}-s-m}{p_{m}-s-m}, \\
p_{m} & =s+(v-s) \bar{F}\left(Q_{m}\right) .
\end{aligned}
$$

Therefore, the RE equilibrium quantity $Q_{m}$ and price $p_{m}$ must satisfy

$$
\begin{aligned}
\bar{F}\left(Q_{m}\right) & =\frac{\chi\left(w^{*}-s\right)}{\left(p_{m}-p^{*}\right)+\chi\left(p^{*}-s\right)} \\
p_{m} & =s+(v-s) \bar{F}\left(Q_{m}\right) .
\end{aligned}
$$

The solution to this pair of equations can not have $p_{m}>p^{*}$ because this implies, by comparing (EC.5) and (EC.11), that $\bar{F}\left(Q_{m}\right)<\bar{F}\left(Q_{q}^{*}\right)$, which in turn implies, by comparing (EC.6) and (EC.12), that $p_{m}<p^{*}$, thereby raising a contradiction. Similarly, we can not have $p_{m}<p^{*}$. Therefore, in equilibrium, we must have $p_{m}=p^{*}$ and $Q_{m}=Q_{q}^{*}$. This equilibrium attains the optimal profit benchmark $\Pi_{q}^{*}$. Notice from (EC.7) that the required condition $w_{m}-s-m>0$ holds true because $w^{*} \geq c>s$.

Next, we show that setting $\chi=\lambda / \lambda^{*}$ yields the desired profit allocation. The retailer's equilibrium profit is

$$
\Pi_{m}^{r}\left(Q_{m}, p_{m}\right)=\left(p_{m}-s-m\right) E\left(X \wedge Q_{m}\right)-\left(w_{m}-s-m\right) Q_{m}
$$




$$
\begin{aligned}
& =\left(p^{*}-s-m\right) E\left(X \wedge Q_{q}^{*}\right)-\left(w_{m}-s-m\right) Q_{q}^{*} \\
& =\frac{\lambda}{\lambda^{*}}\left\{\left(p^{*}-s\right) E\left(X \wedge Q_{q}^{*}\right)-\left(w^{*}-s\right) Q_{q}^{*}\right\} \\
& =\frac{\lambda}{\lambda^{*}} \cdot \lambda^{*} \Pi_{q}^{*} \\
& =\lambda \Pi_{q}^{*},
\end{aligned}
$$

as required. Finally, with $\chi=\lambda / \lambda^{*}$, solving (EC.7) and (EC.8) yields the desired parameters $w_{m}, m$.

Proof of Proposition 8 The contract parameters given in the proposition are

$$
w_{m}=\left(1-\frac{\lambda}{\lambda^{*}}\right) p^{*}+\frac{\lambda}{\lambda^{*}} w^{*} \text { and } m=\left(1-\frac{\lambda}{\lambda^{*}}\right)\left(p^{*}-s\right) .
$$

Observe that $m \geq 0$ if and only if $\lambda \leq \lambda^{*}$, so this yields our two cases. Part (i) follows directly from Proposition 7. In (ii), we use $w_{r}=w_{m}+|m|$ and $r=|m|$ to find the required parameters.

Proof of Proposition 9 Recall that the retailer faces the profit function

$$
\Pi_{b}^{r}(Q)=(v-b) E(X \wedge Q)-\left(w_{b}-b\right) Q
$$

so the optimal stocking quantity is

$$
\bar{F}\left(Q_{b}^{r}\right)=\left(w_{b}-b\right) /(v-b)
$$

Recall also that the supply chain profit function is

$$
\Pi_{b}(Q)=v E(X \wedge Q)-c Q
$$

which is maximized at $Q_{b}$, as characterized by

$$
\bar{F}\left(Q_{b}\right)=c / v
$$

The proof follows the standard approach in the supply chain contracting literature, so we shall keep it brief. The appropriate buyback contract has two objectives: (i) to induce $Q_{b}^{r}=Q_{b}$ (coordination) and (ii) to yield a $(\lambda, 1-\lambda)$ division of profits (allocation). The two conditions $v-b=\lambda v$ 
and $w_{b}-b=\lambda c$ together achieve both objectives because: (i) $\frac{w_{b}-b}{v-b}=\frac{\lambda c}{\lambda v}=\frac{c}{v}$, so from (EC.15) and (EC.17), we have $Q_{b}^{r}=Q_{b}$, and (ii) from (EC.14) and (EC.16), we have $\Pi_{b}^{r}(Q)=(v-b) E(X \wedge Q)-$ $\left(w_{b}-b\right) Q=\lambda v E(X \wedge Q)-\lambda c Q=\lambda \Pi_{b}(Q)$. Solving these two equations yields the desired contract parameters. Finally, since $b=(1-\lambda) v$, the condition $b \geq s$ yields the upper bound of $1-\frac{s}{v}$ on the retailer's share $\lambda$.

Extension of $R E$ equilibrium to heterogeneous customers First, let $\xi_{\text {prob, } \theta}(p)$ denote type- $\theta$ 's beliefs over the probability of availability on the salvage market. Based on these beliefs, let $r_{\theta}(p)$ denote type- $\theta$ 's reservation price. Next, we introduce the seller's beliefs. Let $\xi_{r_{\theta}}(p)$ be the seller's beliefs of type- $\theta$ 's reservation prices. Similarly, let $\xi_{\alpha}(p)$ denote the seller's belief on the fraction of customers who will buy early at the price $p$.

Now, let $\alpha(p)$ and $\beta(u, p)$ respectively denote the fraction of customers who buy early and the fraction of customers who will be served after type- $u$ (if he waits), given the reservation prices $r_{\theta}(p)$ and actual price $p$. In other words, we have $\alpha(p) \equiv \int_{\left\{\theta: r_{\theta}(p) \geq p\right\}} d G(\theta)$ and $\beta(u, p) \equiv$ $\int_{\left\{\theta: r_{\theta}(p)<p \text { and } \theta \leq u\right\}} d G(\theta)$.

We shall use $\Pi(Q, p ; \alpha)$ to denote the standard newsvendor profit function with stocking quantity $Q$, price $p$, and demand $\alpha X$ (i.e. when the fraction of customers who buy early is $\alpha$ ). Similarly, let $Q^{*}(p, \alpha)$ and $\Pi^{*}(p, \alpha)$ denote the optimal order quantity and optimal profit in the standard newsvendor model with price $p$ and demand $\alpha X$.

Definition EC.1. A RE equilibrium consists of $\left(p, Q, r_{\theta}(p), \xi_{p r o b, \theta}(p), \xi_{r_{\theta}}(p)\right)$. The RE equilibrium conditions are:

(i) $r_{\theta}(p)= \begin{cases}v_{\theta}-\left(v_{\theta}-s\right) \xi_{p r o b, \theta}(p), & Q>0, \\ 0, & Q=0,\end{cases}$

(ii) $p=\arg \max _{p} \Pi^{*}\left(p, \xi_{\alpha}(p)\right)$,

(iii) $Q=Q^{*}\left(p, \xi_{\alpha}(p)\right)$,

(iv) $\xi_{\text {prob }, \theta}(p)= \begin{cases}F\left(\frac{Q}{\alpha(p)}\right), & r_{\theta}(p) \geq p, \\ F\left(\frac{Q}{1-\beta(\theta, p)}\right), & r_{\theta}(p)<p,\end{cases}$

(v) $\xi_{r_{\theta}}(p)=r_{\theta}(p)$.

These RE conditions have the same interpretation as before. Condition (i) determines customers' reservation prices, given their beliefs on availability probabilities as a function of the price that 
they have observed. Conditions (ii) and (iii) solves for the seller's optimal price and quantity, given their beliefs on reservation prices. Finally, conditions (iv) and (v) are consistency conditions.

The following lemma shows that in any RE equilibrium, the reservation prices must exhibit what we call a threshold property. That is, for any price $p$, there must be some marginal type $\varphi(p)$ such that only customers with higher types are willing to buy.

Lemma EC.1. Suppose that the reservation prices $r_{\theta}(p)$ are part of a $R E$ equilibrium. Then, there exists some function $\varphi(p)$ such that

$$
\begin{aligned}
& r_{\theta}(p) \geq p, \quad \theta \geq \varphi(p), \\
& r_{\theta}(p)<p, \quad \theta<\varphi(p) .
\end{aligned}
$$

Proof of Lemma EC.1 Suppose that there is some price $p$ at which types $\theta_{1}$ and $\theta_{2}$ are willing to buy early, but not anyone in between (where $\theta_{1}<\theta_{2}$ ). The RE equilibrium conditions (i) and (iv) tell us that $p \leq r_{\theta_{1}}(p)<r_{\theta_{2}}(p)$. On the other hand, $r_{\theta}(p) \rightarrow r_{\theta_{2}}(p)$ as $\theta \rightarrow \theta_{2}^{-}$, so there must be some types close enough to (but below) $\theta_{2}$ who are willing to buy as their reservation price exceeds $r_{\theta_{1}}(p)$. This yields the desired contradiction. 


\section{Supplementary Appendix B: Numerical Studies}

In this online appendix, we present some numerical results of the heterogeneous model introduced in Section 6.1. The customer pool is heterogeneous and indexed by $\theta \in[0,1]$. For each type $\theta$, there is an associated valuation $v_{\theta}$, which is increasing in $\theta$. That is, a higher type is associated with

a higher valuation. Assume the range of the valuation is $\left[v_{0}, v_{1}\right]$ and $c<v_{0}$. Let $G(\theta)$ denote the proportion of customers of type $\theta$ and below (i.e., customers with valuations not exceeding $v_{\theta}$ ). The total demand $X$ follows distribution $F$. In other words, the number of customers with valuations not exceeding $v_{\theta}$ is given by the random variable $G(\theta) X$.

The focus of this online appendix is on a decentralized supply chain under a wholesale price contract $w$. We are interested to know how the retailer's, the manufacturer's, and the supply chain's profits vary as $w$ increases. In particular, we want to know if the result that decentralization may improve supply chain efficiency still holds when the retailer faces customers with heterogeneous valuations. Below we show the figures for two particular examples, one with uniformly distributed customer valuations (i.e., $G$ is a uniform distribution) and the other with normally distributed valuations (i.e., $G$ is a normal distribution). We have tested many more examples, and the results are very similar and therefore omitted.

In the first example, we use the following parameters: $c=4.5, s=4, F$ is normal distribution $N(100,400)$, and $G$ is uniform on $[6,10]$. Note that Figure 1 in the main text of the paper (Section 4.1) uses exactly the same parameters except that $v$ is fixed at 8 rather than follow a uniform distribution with a mean 8. According to Section 6.1, for a given wholesale price $w$, the retailer optimizes her profit in the RE equilibrium by choosing a price $p$. We search for the optimal $p$ for the retailer for each $w$ and calculate the corresponding equilibrium quantity and profit for the retailer. Similarly, we calculate the manufacturer's and the supply chain's profits for each $w$. Figure EC.1 shows the three profit functions against the horizontal axis $w$.

We can see that Figure EC.1 displays some similar properties to those of Figure 1 in the main text: first, the supply chain profit rises as $w$ increases, indicating that double marginalization 


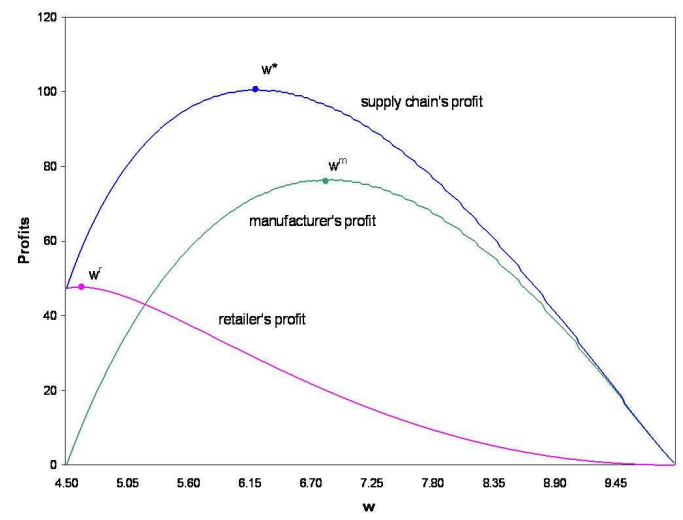

Figure EC.1 Comparison of the profit functions (demand follows a normal distribution $N(100,400)$ and parameter values are $c=4.5, s=4$, and $v \sim U[6,10])$.

improves supply chain efficiency; second, since $w^{r}>c$ (recall $w^{r}$ is the profit-maximizing wholesale price for the retailer), we know that the retailer may prefer a higher wholesale price when facing strategic customers. Therefore, the introduction of heterogeneous customer valuations does not remove the driving force underlying our counter-intuitive result: with the presence of strategic customers, double marginalization help the retailer credibly reduce her order quantity and thus improve the retailer's and the supply chain's profits.

In the second example, everything is the same as before but now $G$ follows a truncated normal distribution on $[6,10]$ (the mean is again 8 , the standard deviation is $2 / 3$, and the truncated probability is evenly distributed over the support). Figure EC.2 shows the three profit functions over $w$ and we can see that the qualitative results are similar.

\section{Acknowledgments}

The authors would like to thank Gerard Cachon, Fangruo Chen, Rachel Chen, Cuihong Li, William Lovejoy, Serguei Netessine, Erica Plambeck, Terry Taylor, Miguel Villas-Boas, Candace Yano, Shuya Yin and Hao Zhang for their helpful comments as as well as the Associate Editor and reviewers and seminar participants at Hong Kong University of Science and Technology, Shanghai Jiaotong University, University of California, Irvine, Washington University in St. Louis, the MSOM 2006 Conference in Atlanta, Georgia, and the Informs Annual Meeting 2006 in Pittsburgh, Pennsylvania. 


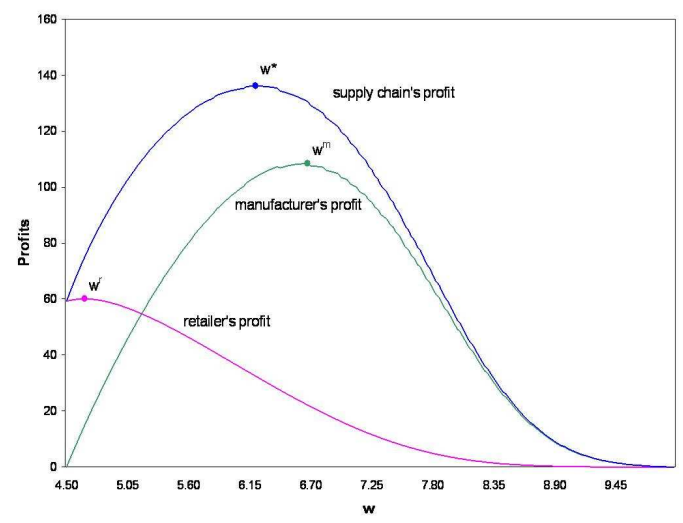

Figure EC.2 Comparison of the profit functions (demand follows a normal distribution $N(100,400)$ and parameter values are $c=4.5, s=4$, and $v$ follows a truncated normal distribution on $[6,10])$. 